NBER WORKING PAPER SERIES

A THEORY OF LIQUIDITY AND REGULATION OF FINANCIAL INTERMEDIATION

\author{
Emmanuel Farhi \\ Mikhail Golosov \\ Aleh Tsyvinski \\ Working Paper 12959 \\ http://www.nber.org/papers/w12959
NATIONAL BUREAU OF ECONOMIC RESEARCH
1050 Massachusetts Avenue
Cambridge, MA 02138
March 2007

Golosov and Tsyvinski acknowledge support by the National Science Foundation. We thank Daron Acemoglu, Stefania Albanesi, Franklin Allen, Marios Angeletos, Ricardo Caballero, V.V. Chari, Ed Green, Christian Hellwig, Skander Van den Heuvel, Oleg Itskhoki, Bengt Holmstrom, Guido Lorenzoni, Chris Phelan, Bernard Salanie, Jean Tirole, Ivan Werning, and Ruilin Zhou for comments. We also thank the audiences at the Bank of Canada, Minneapolis Federal Reserve, Harvard, MIT, UT Austin, Wharton, and Society of Economic Dynamics for useful comments. The views expressed herein are those of the author(s) and do not necessarily reflect the views of the National Bureau of Economic Research.

(C) 2007 by Emmanuel Farhi, Mikhail Golosov, and Aleh Tsyvinski. All rights reserved. Short sections of text, not to exceed two paragraphs, may be quoted without explicit permission provided that full credit, including $\odot$ notice, is given to the source. 
A Theory of Liquidity and Regulation of Financial Intermediation

Emmanuel Farhi, Mikhail Golosov, and Aleh Tsyvinski

NBER Working Paper No. 12959

March 2007

JEL No. E6,G18,G2,G28

\begin{abstract} markets for aggregate shocks.

Emmanuel Farhi

Department of Economics

Harvard University

Littauer Center

1837 Cambridge St.

Cambridge, MA 02138

efarhi@fas.harvard.edu

Mikhail Golosov

MIT Department of Economics

E52-243G

50 Memorial Drive

Cambridge, MA 02142

and NBER

golosov@mit.edu

\author{
Aleh Tsyvinski \\ Department of Economics \\ Harvard University \\ Littauer Center \\ 1837 Cambridge St. \\ Cambridge, MA 02138 \\ and NBER \\ tsyvinski@harvard.edu
}

This paper studies a mechanism design model of financial intermediation. There are two informational frictions: agents receive unobservable shocks and can participate in markets by engaging in trades unobservable to intermediaries. Without regulations, intermediaries provide no risk sharing because of an externality arising from arbitrage opportunities. We identify a simple regulation -- a liquidity requirement -- that corrects such an externality by affecting the interest rate on the markets. We characterize the form of the optimal liquidity adequacy requirement for a general class of preferences. We show that whether markets underprovide or overprovide liquidity, and whether a liquidity cap or a liquidity floor should be used depends on the nature of the shocks that agents experience. Moreover, we prove that the optimal liquidity adequacy requirement implements a constrained efficient allocation subject to unobservable types and trades. We provide closed form solutions for the optimal liquidity requirement and welfare gains of imposing such requirements for two important special cases. In contrast with the existing literature, the necessity of regulation does not depend on exogenous incompleteness of 


\title{
A Theory of Liquidity and Regulation of Financial Intermediation
}

\author{
Emmanuel Farhi, Mikhail Golosov, and Aleh Tsyvinski*
}

February 23, 2007

\begin{abstract}
This paper studies a mechanism design model of financial intermediation. There are two informational frictions: agents receive unobservable shocks and can participate in markets by engaging in trades unobservable to intermediaries. Without regulations, intermediaries provide no risk sharing because of an externality arising from arbitrage opportunities. We identify a simple regulation - a liquidity requirement - that corrects such an externality by affecting the interest rate on the markets. We characterize the form of the optimal liquidity adequacy requirement for a general class of preferences. We show that whether markets underprovide or overprovide liquidity, and whether a liquidity cap or a liquidity floor should be used depends on the nature of the shocks that agents experience. Moreover, we prove that the optimal liquidity adequacy requirement implements a constrained efficient allocation subject to unobservable types and trades. We provide closed form solutions for the optimal liquidity requirement and welfare gains of imposing such requirements for two important special cases. In contrast with the existing literature, the necessity of regulation does not depend on exogenous incompleteness of markets for aggregate shocks.
\end{abstract}

Keywords: Optimal Regulations, Financial Intermediation, Optimal Contracts, Market Failures, Mechanism Design.

\section{Introduction}

The role of financial intermediaries in providing liquidity is one of the central features of a modern financial system. Accordingly, the regulation of financial intermediaries is an important function of central banks and is a topic of frequent debates in the policy-making community. In this paper we

${ }^{*}$ Farhi: Harvard University; Golosov: MIT and NBER; Tsyvinski: Harvard and NBER. Golosov and Tsyvinski acknowledge support by the National Science Foundation. We thank Daron Acemoglu, Stefania Albanesi, Franklin Allen, Marios Angeletos, Ricardo Caballero, V.V. Chari, Ed Green, Christian Hellwig, Skander Van den Heuvel, Oleg Itskhoki, Bengt Holmstrom, Guido Lorenzoni, Chris Phelan, Bernard Salanié, Jean Tirole, Ivan Werning, and Ruilin Zhou for comments. We also thank the audiences at the Bank of Canada, Minneapolis Federal Reserve, Harvard, MIT, UT Austin, Wharton, and Society of Economic Dynamics for useful comments. 
answer several important questions. Can markets provide the correct amount of liquidity? What is a precise nature of market failure if such exists? Can a regulator design a simple policy to improve on the allocations provided by competitive markets alone? The questions of public versus private provision of liquidity, limits of the markets in the provision of liquidity, and the role of government in regulation of financial intermediation has been a subject of considerable volume of recent research. Most notably, Holmstrom and Tirole (1998) and Allen and Gale (2004) study models of provision of liquidity in the presence of either informational or enforcement frictions.

We study a mechanism design model of financial intermediaries as providers of liquidity similar to Diamond and Dybvig (1983) and Allen and Gale (2004). In our setup, agents receive unobservable taste shocks. ${ }^{1}$ Intermediaries invest in short and long term assets and offer a risk-sharing contract that pools risk across agents. An environment in which the only informational friction is unobservability of agents' types is well analyzed in the literature. It is easy to show, as in Prescott and Townsend (1984) and Allen and Gale (2004), that markets provide optimal allocations, and, therefore, there is no role for government intervention.

The focus of this paper is on an environment in which there is an additional informational friction: consumers can trade assets unobservably on a private market by engaging in hidden side trades. Since the contribution of Jacklin (1987), the possibility of agents engaging in hidden side trades has been recognized as an important constraint on the provision of liquidity by financial intermediaries. $^{2}$ Unobservability of consumption arising from a possibility of such trades is a realistic and significant friction affecting liquidity. It is difficult, if not impossible, for an individual financial intermediary to control the exact use of funds or consumption of an agent or preclude a firm from engaging in beneficial trades with other firms in the economy. A different interpretation of unobservability of consumption is non-exclusivity of contracts. It is difficult for an individual financial intermediary to preclude an agent to enter in additional risk sharing contracts with other intermediaries. Possibility of hidden trades can significantly worsen and even eliminate risk sharing. For example, Jacklin (1987) and, more recently, Allen and Gale (2004) showed that absent any government regulations, in an environment with unobservable trades, intermediaries provide no risk sharing. Allen and Gale (2004) then conclude that, in the absence of aggregate shocks and incompleteness of the markets for aggregate risk, there is no regulation that can improve upon the market equilibrium.

In contrast to the literature, we propose and analytically characterize a simple intervention that can improve upon the market allocations. We propose imposing a liquidity requirement that stipulates either the minimal (liquidity floor) or the maximal (liquidity cap) amount of liquidity - holdings of the short asset - for an intermediary. Such regulation affects the interest rate on the hidden trade market, relaxes incentive compatibility constraints, and improves welfare. Im-

\footnotetext{
${ }^{1}$ Agents in our setup can be also thought of as as firms or entrepreneurs experiencing shocks to their productive opportunities. The interpretation of our environment as a model of firms makes the paper similar to the setup of liquidity provision in the productive sector by Holmstrom and Tirole (1998).

${ }^{2}$ The importance of access to credit markets as a constraint on the optimal program was also emphasized by Allen (1985) and Chiappori, Macho, Rey, and Salanie (1994).
} 
portantly, we also show that the optimal liquidity adequacy requirement implements the efficient allocation in which the social planner is constrained by the unobservability of agents' types and the possibility of hidden trades. Therefore, the optimal liquidity adequacy requirement is not just the best requirement within a particular class of interventions, i.e. within a class of liquidity adequacy requirements. It is also an intervention that allows to achieve the highest possible welfare subject to these two information frictions. We identify a reason for the market failure - an externality in which intermediaries do not internalize how liquidity they provide affects other intermediaries via the possibility of trades on private markets. Importantly, this externality exists even when there are no aggregate shocks. This contrasts with the conclusions of Holmstrom and Tirole (1998) and Allen and Gale (2004) that the government has a role in regulating liquidity only if there are aggregate shocks.

A technical contributions of the paper is an analytical characterization of the optimal liquidity regulation in terms of easily interpretable wedges and determination of the form of the optimal regulation (liquidity cap or liquidity floor) for a general specification of preferences. We also provide a closed form solution for the optimal regulation in two cases: for a setup with logarithmic utility and for the environment studied by Diamond and Dybvig (1983).

We prove that the particular form of preference shocks one assumes is crucial to determine the direction of the optimal liquidity requirement. The intuition for why a liquidity requirement improves upon a competitive market allocation is that it affects prices (interest rates in our case) on private markets. In short, a change in the interest rate affects the deviating agent who simultaneously claims a different type and engages in hidden trades more than an agent who truthfully announces his type, therefore, relaxing the incentive compatibility constraints. The direction of the deviation depends on the specification of the preference shocks. In the case of the liquidity shocks, a deviating agent wants to save. A liquidity floor reduces the interest rate and makes borrowing less attractive. In the case of discount shocks, a deviating agent wants to borrow. A liquidity cap increases the interest rate and makes saving less attractive.

Our model suggests practical implications for regulation of financial intermediation. Various types of intermediaries or different regions in a country, depending on the primary nature of the shocks that the agents whom they serve experience, should have different forms of liquidity regulations. There are two appealing features of liquidity requirements that make it suitable for policy implementation. First, it is simple to implement as it specifies only how much liquidity intermediaries should hold in the first versus second period. Intermediaries are then left to determine how they service their individual consumers without any additional government intervention. Second, it does not shut down private markets. Rather, aggregate manipulation of liquidity endogenously changes the interest rate on these markets.

We structure the paper to follow the discussion of equilibria and efficiency concepts progressing from less constrained to more constrained problems. The least restrictive program is an optimal allocation subject only to feasibility constraint $\left(S P^{1}\right)$ - in this setup, there is no private information. We then characterize a competitive equilibrium $\left(C E^{2}\right)$ and a constrained efficient allocation $\left(S P^{2}\right)$ 
in which the only informational friction is unobservable types. As we discussed above, the welfare achieved by $C E^{2}$ is equal to welfare achieved by $S P^{2}$. We then describe a competitive equilibrium $\left(C E^{3}\right)$ for the case when types are unobservable, and agents can also engage in hidden trades. We characterize the form of the optimal liquidity adequacy requirement depending on the specification of preferences. We then show that the optimal liquidity adequacy requirement implements the constrained efficient allocation $S P^{3}$ in which a planner is constrained by two informational frictions

- private types and hidden trades. Generically, welfare is higher in the solution to $S P^{3}$ than welfare achieved by competitive markets $C E^{3}$. For an important special case, considered in Diamond and Dybvig (1983) and Jacklin (1986), competitive equilibria without regulations imply no risk sharing and autarchic allocations while the optimal liquidity adequacy achieves welfare of the unconstrained problem $S P^{1}$ (in fact, the solutions to all three programs $S P^{1}, S P^{2}$, and $S P^{3}$ coincide in this particular case). ${ }^{3}$

\section{Relationship to the literature}

This paper builds on a large literature of risk sharing by in the presence of liquidity shocks (Diamond and Dybvig 1983; Jacklin 1987; Bhattacharya and Gale 1987; Hellwig 1994; Diamond 1997; Von Thadden 1999; Caballero and Krishnamurthy 2003; Allen and Gale 2003, 2004 ${ }^{4}$ ). More generally, our paper fits in the literature of optimal allocations with unobservable taste shocks following Atkeson and Lucas (1992).

Our paper uses the mechanism design framework of an important paper by Allen and Gale (2004) to analyze the model of intermediation in the presence of private markets. Our results in the model with private markets differ significantly from their work. The result of Allen and Gale (2004) that an equilibrium is inefficient relies on exogenously imposed incompleteness of markets for trades among intermediaries when there are aggregate shocks. In the absence of incomplete markets for aggregate shocks or in the absence of aggregate shocks, Allen and Gale (2004) conclude that there is no role for regulation of liquidity or any other regulatory intervention. We show that a liquidity requirement can improve upon the competitive equilibrium by eliminating above described externality even when there are complete markets for aggregate shocks or when there are no aggregate shocks. The mechanism of how liquidity requirements affects interest rates on private markets and the characterization of the optimal liquidity adequacy requirement is new to the literature on the provision of liquidity by financial intermediaries. Moreover, we provide a theoretical characterization of the optimal liquidity adequacy requirement for a general specification of shocks and closed form solutions for two important cases.

Our paper shares a common goal with the work of Allen and Gale (2004) in studying whether laissez-faire markets provide too little or too much liquidity and whether a specific policy interven-

\footnotetext{
${ }^{3}$ We use terminology $S P^{1}, S P^{2}$, and $S P^{3}$ to correspond to what in the literature is, somewhat imprecisely, called first-, second-, and third-best problems. The advantage of our notation is that we clearly define constraints that a social planner faces.

${ }^{4}$ For a survey of the literature see Freixas and Rochet (1997) and Gorton and Winton (2002).
} 
tion that occurs at an aggregate level can be Pareto improving or even optimal. Both of the papers direct regulations at intermediaries rather than individual consumers. A government regulates intermediaries while intermediaries on their own solve incentive problems via direct interactions with consumers.

Holmstrom and Tirole (1998) provide a theory of liquidity in a model in which intermediaries have borrowing frictions. Similar to our paper they do not assume incomplete markets. In their model, a government has an advantage over private markets as it can enforce repayments of borrowed funds while the private lenders cannot. They show that availability of government provided liquidity leads to a Pareto improvement when there is aggregate uncertainty. The role of the government in our model is to correct an inefficiency arising because of an externality associated with private information and possibility of hidden trades. In our paper, in contrast with Holmstrom and Tirole (1998) and Allen and Gale (2004), a liquidity requirement improves upon a market allocation even when there is no aggregate uncertainty.

Our paper also differs conceptually from the seminal paper of Jacklin (1987). That paper compares a competitive equilibrium with private markets $\left(C E^{3}\right)$ to the social optimum without private market $\left(S P^{2}\right)$ which is, essentially, equivalent to the statement that prohibition of private markets leads to a Pareto improvement. In our paper, we find the optimal liquidity requirement and show that it implements the solution of the social planner's problem who is faced with both unobservable types and private markets $\left(S P^{3}\right)$ which, for this specification of preferences, coincides with $S P^{1}$ and $S P^{2}$. In contrast with Jacklin, there is no need to prohibit private markets to achieve superior or even unconstrained allocations. A regulator can impose a liquidity adequacy requirement that achieves such optimal allocations.

Lorenzoni (2006) considers a Diamond-Dybvig model of banking with financial markets. His results on the characterization of the optimum is similar to our results for the special case of Diamond-Dybvig setup. The focus of Lorenzoni (2006) is on the models of money and on implementation of the optimum and advantages of various policy interventions. In his model, a specification of technology for intertemporal transfer of resources allows him to consider tradeoffs of various policy interventions. Another paper that is related to our results in the Diamond-Dybvig setup is Caballero and Krishnamurthy (2003). They develop a model of an emerging market crisis in which there is a market for external borrowing and a domestic private market. The domestic market in their model is similar to the private market in our formulation. They show that the equilibrium coincides with the optimal allocation in the presence of private markets. They further show that a range of financial instruments including liquidity requirements and taxes on external borrowing can implement the optimal allocation without private markets that coincides with the full information optimum. In our general model, a competitive equilibrium with the optimal liquidity adequacy requirement is different from the competitive equilibrium without private markets and, therefore, is different from unconstrained "first-best" allocation. However, we show that in a special case of the Diamond and Dybvig (1983) environment, the optimal liquidity regulation implements the unconstrained optimum. 
While the focus of this paper is on the models of financial intermediation, we also contribute to the literature on optimal taxation in the presence of hidden trades ${ }^{5}$. In particular, Golosov and Tsyvinski (2006) study an optimal dynamic Mirrlees taxation with endogenous private markets. There are two main differences between our paper and their work. The first difference is conceptual. In Golosov and Tsyvinski (2006) as in most of the models of dynamic Mirrlees taxation (see, e.g., Golosov, Kocherlakota, and Tsyvinski 2003 or a review in Golosov, Tsyvinski, and Werning 2006 and Kocherlakota 2006), private information (skill shocks) is dynamic and separable from consumption. The inefficiency of the competitive equilibrium in Golosov and Tsyvinski (2006) arises because of the dynamic nature of the private shocks. In our model, private information does not change stochastically over time, and the inefficiency arises due to non-separability of shocks and consumption. The second difference is in the extent of the results that we obtain. Golosov and Tsyvinski (2006) and Bisin et. al. (2001) are able to identify only the direction of a local policy change that leads to a Pareto improvement. We characterize the optimal allocation in the presence of private markets and show that the optimal liquidity regulation implements the optimum $S P^{3}$. We derive an analytical solution for the interest rate associated with the optimal liquidity requirement in terms of an easily interpretable wedge depending on the specification of preferences and distribution of shocks. Moreover, we provide a complete closed form solution for the optimum for two important examples. Studying optimal rather than locally improving interventions is not only interesting from the theoretical point of view. Optimal interventions may achieve a significant improvement in welfare compared to the competitive equilibrium. For example, we show that in the case of Diamond and Dybvig (1983) the optimal liquidity requirement implements the unconstrained optimum.

Related is a recent paper by Albanesi (2006) that studies a model of entrepreneurship and financial assets. The focus of that paper is on an implementation of the optimal program with observable consumption as a competitive equilibrium with taxes in which agents can trade multiple assets. She derives a general result on differential asset taxation in such models.

In Diamond (1997), as in our paper, the optimal allocation is different from autarky. His result relies on the assumption that some consumers are exogenously restricted from participating in private markets. Unlike that paper, in our model all consumers can participate in markets. An elegant paper by Bisin and Rampini (2004) justifies an institution of bankruptcy in a model of non-exclusive contracts. In their work, borrowers (entrepreneurs) have an access to secondary markets. A possibility of default on these secondary contracts worsens return to hidden borrowing and lending and yields a Pareto improvement.

One justification for reserve requirements is found in the existence of deposit insurance. The rationale given is usually as follows: deposit insurance encourages risk taking behavior of intermediaries (see, e.g., Merton 1977) which can be controlled by requiring intermediaries to hold adequate

\footnotetext{
${ }^{5}$ See, for example, Arnott and Stiglitz (1986), (1990), Greenwald and Stiglitz (1986), and Hammond (1987). Several recent papers such as Geanakoplos and Polemarchakis (2004) and Bisin, et. al. (2001) showed in very general settings that economies with asymmetric informations are inefficient and argued for Pareto-improving anonymous taxes.
} 
levels of liquidity. In this argument, existence of one potentially suboptimal policy, deposit insurance, justifies necessity of another policy - reserve requirements. Typically, this literature, with the exception of Hellman, Murdock and Stiglitz (1998, 2000), does not consider optimal policy in the absence of deposit insurance. This literature also does not pose a friction or a market failure and does not find an optimal policy that can be deposit insurance, reserve requirement, some combination of those, or maybe neither. Our results on the optimality of reserve requirements do not rely on the existence of any other exogenously given policy.

\section{Model}

We consider a standard mechanism design model of financial intermediation similar to Diamond and Dybvig (1983) and closest to Allen and Gale (2004). The economy lasts three periods $(t=0,1,2)$ and is populated by a continuum of ex-ante identical agents, or investors.

There are two assets (technologies) in the model. The short asset is a storage technology that returns one unit of consumption good at $t+1$ for each unit invested at $t$. Investment in the long asset has to be done at $t=0$ to yield $\hat{R}$ units of the consumption good at $t=2$. Investors only value consumption at dates 1 and 2 and receive a private idiosyncratic preference shock at the beginning of date 1 . We denote the preference shock by $\theta \in \Theta=\left[\theta_{L}, \theta_{H}\right]$. Investor's preferences are represented by a utility function $u\left(c_{1}, c_{2} ; \theta\right)$, where $c_{t}$ denotes consumption at date $t=1,2$. The utility function $u(\cdot ; \theta)$ is assumed to be concave, increasing, and continuous for every type $\theta$. We also assume a single crossing property:

\section{Assumption 1 (Single crossing): $\frac{\partial}{\partial \theta}\left(\frac{\partial u / \partial c_{2}}{\partial u / \partial c_{1}}\right)>0$.}

In the paper we are primarily interested in studying three types of preferences: discount factor shocks, liquidity shocks, and valuation-neutral shocks. We also provide a complete characterization of the model for the fourth set of preference described in Diamond and Dybvig (1983) and used in Jacklin (1987).

Example 1 Discount factor shocks: $u\left(c_{1}, c_{2} ; \theta\right)=\hat{u}\left(c_{1}\right)+\theta \hat{u}\left(c_{2}\right)$.

In this case, agents differ by how much they value second period consumption. The first feature of these preferences is that a planner would like to allocate a relatively higher amount of second period consumption to an agent with a higher shock $\theta$. The second feature of these preferences is also important to our results. Consider two agents who are allocated the same consumption $c_{1}=c_{2}=\bar{c}$. An agent with higher $\theta$ would receive a higher lifetime utility of consumption from such allocation. This feature of preferences creates an incentive for the planner to allocate, if possible, a higher present value of consumption to the agent with higher $\theta$.

Example 2 Liquidity shocks: $u\left(c_{1}, c_{2} ; \theta\right)=\frac{1}{\theta} \hat{u}\left(c_{1}\right)+\hat{u}\left(c_{2}\right)$. 
In this case, low $\theta$, i.e., a high liquidity shock, is a shock that makes consumption at date 1 particularly valuable. Similar to the case of the discount shocks, the second feature of these preferences is that an agent with lower $\theta$ has a higher lifetime utility of consumption than an agent with lower $\theta .^{6}$

Up to now, we have modelled liquidity and discount shocks as preferences shocks, or in other words, consumption opportunity shocks. We now discuss how we can think of the model as an environment in which firms or entrepreneurs face investment opportunity shocks. The outline of such an extension is as follows. Suppose there is a continuum of investors with identical CARA utilities:

$$
u\left(c_{1}, c_{2}\right)=-\frac{1}{\gamma} \exp \left(-\gamma c_{1}\right)-\frac{\beta}{\gamma} \exp \left(-\gamma c_{1}\right)
$$

for some common discount factor $\beta$. Agents are committed to finance a fixed size - normalized to $1-$ investment opportunity paying out $\frac{\tilde{R}}{\hat{\theta}}$ at date 2 and learn their type at date 1 . It can be easily shown that this model is isomorphic to our model of discount factor shocks with $\theta=\beta \exp \left(-\gamma\left(\frac{\tilde{R}}{\hat{\theta}}+1\right)\right)$.

Imagine now that an entrepreneur is committed to finance a project with a known return normalized to one - at date 2 . They learn the exact resources needed for this investment, $\frac{\tilde{q}}{\hat{\theta}}$, at date 1 . It is now easy to see that this model is isomorphic to our model of liquidity shocks with $\theta=$ $\beta \exp \left(-\gamma\left(1+\frac{\tilde{q}}{\hat{\theta}}\right)\right)$. We can therefore interpret agents receiving taste shocks as investors receiving investment opportunity shocks.

Example 3 Valuation-neutral shocks: Let $\hat{u}(c)=\frac{c^{1-\sigma}}{1-\sigma}$ and

$$
u\left(c_{1}, c_{2} ; \theta\right)=\frac{1-\theta}{\left[\theta^{1 / \sigma}+(1-\theta)^{1 / \sigma} \hat{R}^{\frac{1-\sigma}{\sigma}}\right]^{\sigma}} \hat{u}\left(c_{1}\right)+\frac{\theta}{\left[\theta^{1 / \sigma}+(1-\theta)^{1 / \sigma} \hat{R}^{\frac{1-\sigma}{\sigma}}\right]^{\sigma}} \hat{u}\left(c_{2}\right)
$$

If $\hat{u}(c)=\log (c)$, then

$$
u\left(c_{1}, c_{2} ; \theta\right)=(1-\theta) \hat{u}\left(c_{1}\right)+\theta \hat{u}\left(c_{2}\right) .
$$

In this case, agents differ in how valuable their consumption is across periods, but the second feature of the preferences that we described above is absent here, and all agents value the lifetime consumption stream equivalently. Note that in the case of the log utility, there is no need to normalize preferences by $\hat{R}$, and valuation-neutral preferences do not depend on technology.

\footnotetext{
${ }^{6} \mathrm{~A}$ natural question arises whether uility specification of liquidity shocks $\frac{1}{\theta} \hat{u}\left(c_{1}\right)+\hat{u}\left(c_{2}\right)$ is a renormalization of the discount shocks $\hat{u}\left(c_{1}\right)+\theta \hat{u}\left(c_{2}\right)$, and that by dividing utility in the case of discount shocks by $\theta$ we would arrive to the model with liquidity shocks. It is true that both of preferences have the same marginal rates of substitutions. However, the preferences are different in the direction of the levels of lifetime levels of utilities. In the case of liquidity shocks, it is low $\theta$ that gives an agent a higher lifetime value of consumption. In the case of dicount factor shocks, it is exactly the opposite - high $\theta$ leads to high lifetime value of consumption.
} 
Example 4 Diamond-Dybvig preferences. Let $\theta \in\{0,1\}$ and $1>\rho>\hat{R}^{-1}$ :

$$
U\left(c_{1}, c_{2}, \theta\right)=(1-\theta) u\left(c_{1}\right)+\theta \rho u\left(c_{1}+c_{2}\right) .
$$

In the case of Diamond-Dybvig preferences, agents are of two types: those who need to consume in the first period, and those who are indifferent between consuming in the first and the second period.

We begin by assuming that there is no aggregate uncertainty. The timing of the events is as follows. At $t=0$, all individuals are (ex-ante) identical. At $t=1$, each consumer gets an i.i.d. draw of his type. The probability distribution of being an investor of type $\theta$ is denoted by $F(\theta)$. We assume that the "law of large numbers" holds, and that the cross-sectional distribution of types is the same as the probability distribution $F$. One can, therefore, interpret $F(\theta)$ as the number of agents of type below $\theta$. The realization of a consumer's type is private information. Each consumer has an endowment of $e$ units of a consumption good at time $t=0$, and no endowment at dates 1 and 2 .

We denote by $\left\{c_{1}(\theta), c_{2}(\theta)\right\}$ an allocation of consumption across consumers. An allocation is feasible if it satisfies the feasibility constraint given by

$$
\int\left(c_{1}(\theta)+\frac{c_{2}(\theta)}{\hat{R}}\right) d F(\theta) \leq e
$$

We do not impose a sequential service constraint so there are no bank runs in our model. We also restrict our attention to pure strategies. In what follows, we also consider symmetric equilibria.

\section{Benchmark: equilibrium and constrained efficient allocation with- out private markets}

In this section, we define and characterize a competitive equilibrium for the economy without private markets for hidden trades. In this environment, agents are allocated with consumption allocations depending on their types. Agents cannot engage in any unobservable transaction, and their consumption is therefore observable.

\subsection{Definition of equilibrium $C E^{2}$}

Consider a market with a continuum of intermediaries. We assume throughout the paper that all activities at an intermediary level are observable. In period 0 , before the realization of idiosyncratic shocks, consumers deposit their initial endowment with the intermediary. An intermediary agrees to provide a stream of consumption $\left\{c_{1}(\theta), c_{2}(\theta)\right\}$. These contracts are offered competitively, and there is free entry for intermediaries. Therefore, consumers sign a contract with the intermediary that promises the highest ex-ante expected utility. We denote the equilibrium utility for a consumer by $\underline{U}$. After the contract is signed, a consumer, given his type $\theta$, chooses a reporting strategy $\theta^{\prime}(\theta)$, 
and receives consumption $\left(c_{1}\left(\theta^{\prime} \mid \theta\right), c_{2}\left(\theta^{\prime} \mid \theta\right)\right)$. There are no private markets in which consumers can participate, and agents' actual consumption is equal to the allocated consumption.

We assume that intermediaries can trade bonds $b$ among themselves. Without aggregate uncertainty the market for trades among intermediaries is very simple, and we describe it in this section as it is useful for later extensions to the case of aggregate uncertainty. We denote by $q$ the price of a bond $b$ in period $t=1$ that pays one unit of consumption good in period 2. All intermediaries take this price as given. They also pay dividends $d_{1}, d_{2}$ to its owners. At $t=0$, the intermediary invests $x=\int c_{1}(\theta) d F(\theta)$ in the short asset and $y=\frac{1}{\hat{R}} \int c_{2}(\theta) d F(\theta)$ in the long asset. We consider a symmetric equilibrium.

The maximization problem of the intermediary that faces intertemporal prices $q$ and the reservation utility $\underline{U}$ is

$$
\max _{c, d, y, b} d_{1}+q d_{2}+q b-b / \hat{R}
$$

s.t.

$$
\begin{gathered}
\int\left(c_{1}(\theta)+\frac{c_{2}(\theta)}{\hat{R}}\right) d F(\theta)+d_{1}+d_{2} / \hat{R}+q b-b / \hat{R} \leq e, \\
\int u\left(c_{1}(\theta), c_{2}(\theta), \theta\right) d F(\theta) \geq \underline{U}, \\
u\left(c_{1}(\theta), c_{2}(\theta), \theta\right) \geq u\left(c_{1}\left(\theta^{\prime}\right), c_{2}\left(\theta^{\prime}\right), \theta\right) \text { for } \forall \theta, \theta^{\prime} .
\end{gathered}
$$

In problem (3), an intermediary is maximizing profits subject to three constraints. Constraint (4) is a budget constraint that requires that payments to consumers $\left(c_{1}(\theta), c_{2}(\theta)\right)$, payments of dividends $\left(d_{1}, d_{2}\right)$, and net payments on bonds are feasible. Constraint (5) states that the expected utility of an agent is higher than an equilibrium level of utility. Finally, constraint (6) is an incentive compatibility constraint that states that an agent receives higher utility from truthfully announcing his type $\theta$ rather than announcing any other type $\theta^{\prime}$. In equilibrium, competition among intermediaries forces them to have zero profits. We now define a competitive equilibrium.

Definition 1 A competitive equilibrium $C E^{2}$ is a set of allocations $\left\{c_{1}(\theta), c_{2}(\theta)\right\}$, a price $q$, dividends $\left\{d_{1}, d_{2}\right\}$, bond trades $b$, and a utility level $\underline{U}$ such that

(i) intermediaries choose $\left\{\left\{c_{1}(\theta), c_{2}(\theta)\right\},\left\{d_{1}, d_{2}\right\}, b\right\}$ to solve problem (3) taking $q$ and $\underline{U}$ as given;

(ii) consumers choose a contract that offers them the highest ex-ante utility;

(iii) the aggregate feasibility constraint (2) holds;

(iv) firms make zero profits;

(v) bonds markets clear, $b=0$.

It is easy to show that, in equilibrium, $1 / q=\hat{R}$ and $d_{1}=d_{2}=0$. 


\subsection{Characterization and relationship to an unconstrained problem $S P^{1}$ and to a constrained efficient problem $S P^{2}$}

Intermediaries operate on competitive markets and, therefore, maximize an ex ante expected utility of agents. We can immediately see that the problem of the intermediary (3) in a competitive equilibrium is dual to the problem:

$$
\max _{c_{1}, c_{2}} \int u\left(c_{1}(\theta), c_{2}(\theta), \theta\right) d F(\theta)
$$

s.t. feasibility (2) and incentive compatibility (6) hold.

Problem (7) is a definition of a particular notion of constrained efficiency which we denote by $S P^{2}$. In this problem, a planner receives reports from the agents of their types and provides a menu of consumption allocations $\left\{c_{1}(\theta), c_{2}(\theta)\right\}$ to maximize expected utility of an agent subject to incentive compatibility and feasibility constraints. The only informational friction that this planner faces is unobservability of consumer types $\theta$.

The above result that constrained efficient allocations coincide with the competitive equilibrium does not mean that there is perfect risk sharing as the allocations in the problem $S P^{2}$ have to satisfy the incentive compatibility constraints. It is useful to define an unconstrained problem $S P^{1}$ in which types of agents are observable. In that program the social planner does not face any constraints except for feasibility, i.e., maximizes the objective function in the problem (7) subject

to (2). Obviously, the problem of $S P^{1}$ is weakly less restrictive than problem $S P^{2}$. Therefore, the welfare achieved in $S P^{1}$ is weakly higher than welfare achieved in $S P^{2}$.

We summarize characterization of the solution to the problem (7) and, therefore, the solution of the problem (3) in the proposition that follows. The result is similar to Prescott and Townsend (1984) and Allen and Gale (2004).

Proposition 1 (Optimum and competitive equilibrium with observable consumption) Let $c_{1}(\theta)$ and $c_{2}(\theta)$ be equilibrium allocations in Definition 1. Then competitive equilibrium $C E^{2}$ is constrained efficient, i.e., solves problem $S P^{2}$. Moreover, $\forall \theta \in \Theta$ :

1. If preferences are discount shocks, as in the example $1, \widehat{u}^{\prime}\left(c_{1}(\theta)\right) \geq \hat{R} \theta \widehat{u}^{\prime}\left(c_{2}(\theta)\right)$;

2. If preferences are liquidity shocks, as in the example $2, \widehat{u}^{\prime}\left(c_{1}(\theta)\right) \leq \hat{R} \theta \widehat{u}^{\prime}\left(c_{2}(\theta)\right)$;

3. If preferences are valuation-neutral shocks, as in the example 3, $\theta \widehat{u}^{\prime}\left(c_{1}(\theta)\right)=\hat{R}(1-\theta) \widehat{u}^{\prime}\left(c_{2}(\theta)\right)$;

Proof. In the appendix.

The intuition for the wedge in parts 1 and 2 of the above proposition is as follows. Consider, for example, the case of liquidity shocks. An agent with a low liquidity shock, high $\theta$, has an incentive to report a high liquidity shock, low $\theta$, to receive a higher consumption in period 1. A wedge (implicit tax) between the first and the second period consumption relaxes the incentive constraint by making such deviations more costly. We can contrast the result above with the case 
where the shocks are public information, the solution to the problem $S P^{1}$. In that case, there is no intertemporal wedge, and the Euler equation holds with equality. The case of the valuationpreferences in Part 3 of the proposition is special as the incentive compatibility constraint (6) does not bind. For such preferences, the solution to the problem $S P^{1}$ coincides with the solution to the problem $S P^{2}$, and there is no wedge in the intertemporal valuation for all types. ${ }^{7}$

\section{Competitive equilibrium with private markets}

The allocations described in the previous section may not be achieved if agents can engage in transactions on markets. Allen (1985) and Jacklin (1987) were the first to point out that the possibility of such trades may restrict or even lead to a complete elimination of risk sharing. In this section we define and characterize a competitive equilibrium allocation in the presence of private markets. ${ }^{8}$ We first argue, as in Jacklin (1987) and Allen and Gale (2004), that without regulations financial intermediaries provide no risk sharing. Unlike the previous literature we then identify a precise reason for the absence of insurance, an externality, that, as we show in the sections that follow, can be corrected by liquidity regulations.

\subsection{Private market}

We model unobservability of consumption using the setup of private markets as follows. Consider an environment in which all consumers have access to a market in which they can trade assets among themselves unobservably ${ }^{9}$. Formally, suppose that consumers are offered a menu of contracts $\left\{c_{1}(\theta), c_{2}(\theta)\right\}$. We model private markets as an endowment economy where endowments are allocations that agents receive (possibly by misrepresenting their types). A consumer treats the contract and the equilibrium interest rate $R$ on the private market as given and, given his type $\theta$, chooses his optimal reporting strategy $\theta^{\prime}$ that determines his endowment of consumption $\left(c_{1}\left(\theta^{\prime}\right), c_{2}\left(\theta^{\prime}\right)\right)$. Unlike in the environment without private markets, actual after-trade consumption $\left\{x_{1}(\theta), x_{2}(\theta)\right\}$ may differ from the consumption specified in the contract, since it is impossible to preclude a consumer from borrowing and lending the amount $s(\theta)$ on the private market. It can be easily shown that a consumer trades only a risk free security $s(\theta)$ and solves:

\footnotetext{
${ }^{7}$ Note that not every utility function of the form $\theta \hat{u}\left(c_{1}\right)+(1-\theta) \hat{u}\left(c_{2}\right)$ would imply that the incentive compatibility does not bind. For example, if we did not normalize by $\hat{R}$ and $\theta$ in our definiton of value neutral preferences (1), and instead had

$$
u\left(c_{1}, c_{2}, \theta\right)=\theta c_{1}^{1-\sigma} /(1-\sigma)+(1-\theta) c_{2}^{1-\sigma} /(1-\sigma),
$$

the solution of the problem $S P^{2}$ would feature a wedge in the intertemporal valuation, and the incentive compatibility constraint would bind.

${ }^{8}$ An alternative interpretation of the assumption of the private markets is non-exclusivity by which we mean that it is impossible for an intermediary to observe or control transactions of a consumer with other intermediaries.

${ }^{9}$ All our analysis is easily extended to the case in which agents can trade not only among themselves but also with other intermediaries. This case would bring this model closer to an interpretation as an environment of non-exclusive contracts. Key assumption that allows us to extend our results to that case is that portfolios of the intermediary (investment in short and long assets) are observable while transactions with individual consumers are not observable. Our choice of modelling side trades as private markets allows us to economize on notation without affecting the substance of the results.
} 


$$
\max _{x_{1}(\theta), x_{2}(\theta), s(\theta), \theta^{\prime}} u\left(x_{1}(\theta), x_{2}(\theta) ; \theta\right)
$$

s.t. $\forall i$ :

$$
\begin{gathered}
x_{1}(\theta)+s(\theta)=c_{1}\left(\theta^{\prime}\right), \\
x_{2}=c_{2}\left(\theta^{\prime}\right)+R s(\theta) .
\end{gathered}
$$

We denote the value of this problem by $\tilde{V}\left(\left\{c_{1}(\theta), c_{2}(\theta)\right\}, R, \theta\right)$. We denote by $\theta^{\prime}(\theta)$ the reporting strategy that the agent chooses in the problem above.

An equilibrium in the private market requires that in each period the total endowment of consumption goods be equal to the total after trade consumption for $t=1,2$ :

$$
\int x_{t}\left(\theta^{\prime}(\theta)\right) d F(\theta)=\int c_{t}\left(\theta^{\prime}(\theta)\right) d F(\theta)
$$

Conditional on reports $\theta$, the private market economy is a standard endowment economy. Therefore, aggregate endowments $\int c_{1}\left(\theta^{\prime}\right) d F(\theta)$ and $\int c_{2}\left(\theta^{\prime}\right) d F(\theta)$ determine the interest rate $R$. We now define equilibrium in the private market.

Definition 2 An equilibrium in the private market given the profile of contracts $\left\{c_{1}(\theta), c_{2}(\theta)\right\}$ consists of an interest rate $R$; and, for each agent $\theta$ : strategies $\theta^{\prime}(\theta)$, and allocations $\left\{x_{1}(\theta), x_{2}(\theta), s(\theta)\right\}$ such that

(i) consumers solve problem (8) taking $\left\{\left\{c_{1}(\theta), c_{2}(\theta)\right\}, R\right\}$ as given;

(ii) the feasibility constraints on the private market (11) are satisfied.

We assume that for any menu of contract $\left\{c_{1}(\theta), c_{2}(\theta)\right\}$ that is offered there exists a unique equilibrium.

\subsection{Competitive equilibrium with private markets $C E^{3}$}

In the presence of private markets, intermediaries need to take into account, in addition to unobservable types, that consumers are able to engage in transactions in the private market. Each intermediary chooses payments $\left\{c_{1}(\theta), c_{2}(\theta)\right\}$, pays dividends $d_{1}, d_{2}$, and trades bonds $b$ with other intermediaries. It is important to note that intermediaries take the interest rate on the private market $R$ as given. The maximization problem of the intermediary that faces an intertemporal price $q$, a price on the private market $R$, and a reservation utility $\underline{U}$ is

$$
\max _{c, d, y, b} d_{1}+q d_{2}+q b-b / \hat{R}
$$

s.t.

$$
\begin{gathered}
\int\left(c_{1}(\theta)+\frac{c_{2}(\theta)}{\hat{R}}\right) d F(\theta)+d_{1}+d_{2} / \hat{R}+q b-b / \hat{R} \leq e, \\
\tilde{V}\left(\left\{c_{1}(\theta), c_{2}(\theta)\right\}, R ; \theta\right) \geq \tilde{V}\left(\left\{c_{1}\left(\theta^{\prime}\right), c_{2}\left(\theta^{\prime}\right)\right\}, R ; \theta\right), \forall \theta, \theta^{\prime},
\end{gathered}
$$




$$
\int \tilde{V}\left(\left\{c_{1}(\theta), c_{2}(\theta)\right\}, R, \theta\right) d F(\theta) \geq \underline{U} .
$$

The first constraint in the intermediary's problem is the budget constraint. The second constraint is incentive compatibility that states that, given interest rates $R$, consumers choose to truthfully reveal their types. The last constraint states that the intermediary cannot offer a contract which delivers a lower expected utility than the equilibrium utility $\underline{U}$ from the contracts offered by other intermediaries. In equilibrium, all intermediaries act identically and make zero profits. The intermediary's problem in this economy is very similar to that in the economy with observable trades. The only difference comes from the fact that the incentive constraint (14) takes into account side trades that are not observable. The definition of the competitive equilibrium is parallel to that in the economy with observable trades.

Definition $3 A$ competitive equilibrium $C E^{3}$ is a set of allocations $\left\{c_{1}(\theta), c_{2}(\theta)\right\}$, a price $q$, dividends $\left\{d_{1}, d_{2}\right\}$, bond trades $b$, utility $\underline{U}$, and the interest rate on the private market $R$ such that

(i) intermediaries choose $\left\{\left\{c_{1}(\theta), c_{2}(\theta)\right\},\left\{d_{1}, d_{2}\right\}, b\right\}$ to solve problem (12) taking $q, R$, and $\underline{U}$ as given;

(ii) consumers choose the contract that offers them the highest ex-ante utility;

(iii) the aggregate feasibility constraint (2) holds;

(iv) the private market, given the menus $\left\{c_{1}(\theta), c_{2}(\theta)\right\}$, is in equilibrium, and $R$ is an equilibrium price;

(v) firms make zero profits;

(vi) bonds markets clear, $b=0$.

First, we show a straightforward lemma that the incentive compatibility constraint (14) takes the form of equalizing present value of intertemporal allocations across periods because, otherwise, an agent would pretend to claim a type that gives a higher present value of allocations and engage in trades on the private markets to achieve desired consumption allocations.

Lemma 1 An allocation of consumptions satisfies incentive compatibility constraint (14) iff

$$
c_{1}(\theta)+\frac{c_{2}(\theta)}{R}=c_{1}\left(\theta^{\prime}\right)+\frac{c_{2}\left(\theta^{\prime}\right)}{R} \text { for any } \theta, \theta^{\prime} .
$$

Let us rewrite the problem of the intermediary in a more manageable form by considering its dual, simplifying incentive compatibility constraint using Lemma 1, and using the fact that $d_{1}=d_{2}=b=0$ to reduce to:

$$
\max _{c_{1}, c_{2}} \int u\left(c_{1}(\theta), c_{2}(\theta), \theta\right) d F(\theta)
$$

s.t. (16) and

$$
\int\left(c_{1}(\theta)+\frac{c_{2}(\theta)}{\hat{R}}\right) d F(\theta) \leq e .
$$


It is easy to see that the interest rates on the markets for trades among intermediaries must be equal to the return on the production technology, so that $1 / q=\hat{R}$. We now argue that $R=\hat{R}$, otherwise, arbitrage opportunities are created. For example, suppose that $R<\hat{R}$, i.e., an interest rate on the private market is lower than $R$. An intermediary then chooses to invest only in the long asset and sets $\int \frac{c_{2}(\theta)}{\hat{R}} d F(\theta)=e$ and $\int c_{1}(\theta) d F(\theta)=0$. Consumers then can borrow on the private market at the interest rate $R$ that is lower than the technological rate of return $\hat{R}$ available to the intermediary. Therefore, the only price that can be an equilibrium price is $R=\hat{R}$ so that intermediaries do not engage in arbitrage. We can summarize this reasoning in the following proposition.

Proposition 2 (Absence of risk-sharing without regulations) Let $R^{*}$ denote equilibrium price on the private market corresponding to the competitive equilibrium in Definition 3. Then $R^{*}=\hat{R}$. The only allocation that competitive markets can achieve in such an economy is an autarcic allocation in which the present values of endowments evaluated at $\hat{R}$ are equated across different types:

$$
c_{1}(\theta)+\frac{c_{2}(\theta)}{\hat{R}}=c_{1}\left(\theta^{\prime}\right)+\frac{c_{2}\left(\theta^{\prime}\right)}{\hat{R}} \text { for any } \theta, \theta^{\prime} .
$$

This proposition implies that there is complete absence of risk sharing as in Jacklin (1987) and Allen and Gale (2004). There are two important concepts that this proposition summarizes. The first is that the incentive compatibility constraints (arising because of unobservability of types and possibility of trades) lead to equalization of present values of consumptions evaluated at the interest rate on the private market $R$. The second fact is that arbitrage among competitive intermediaries forces the equilibrium interest rate on the private market to be equal to the return on savings $\hat{R}$.

Intuitively, the reason that the competitive equilibrium achieves only an autarcic allocation is an externality. Intermediaries do not take into account how the contracts offered to its investors affect the return on trades and thus incentives to reveal information truthfully for consumers of other intermediaries. Individual intermediaries can not internalize this effect. Competition between different intermediaries implies that interest rates at which consumers trade are equated to $\hat{R}$. The interpretation of our result is different from Jacklin (1987) and Allen and Gale (2004) as we describe it as an externality that we show in the next section can be corrected by a government intervention.

\section{Optimal liquidity requirements}

In this section we show that there exists an intervention - a liquidity requirement - imposed on intermediaries that improves upon the competitive equilibrium allocation. We then determine the best (optimal) liquidity requirement. We show how the form of the optimal liquidity adequacy depends on the nature of the shocks that agents experience. Finally, we show that the best liquidity requirement implements a particular notion of constrained efficient allocations. The key concept in this section is that a manipulation of liquidity leading to changes in the interest rate on private 
markets, may lead to an improvement of risk sharing even in the presence of trading possibilities by agents contrasting with the results of Jacklin (1987) and Allen and Gale (2004).

\subsection{Definition and effects of a liquidity requirement}

A liquidity requirement is a constraint imposed on all intermediaries, i.e., a constraint on the problem (12) that requires that investment in the short asset for any intermediary should be higher (lower) than a level $i$

$$
\left(\int c_{1}(\theta) d F(\theta)\right) \stackrel{\geq}{\leq}
$$

We call a liquidity requirement a liquidity cap if (19) is imposed with less or equal sign. A liquidity cap stipulates the maximal amount of the short asset that an intermediary can hold. We call a liquidity requirement a liquidity floor if (19) is imposed with a greater or equal sign. A liquidity floor stipulates the minimal amount of the short asset that an intermediary can hold. An attractive feature of the liquidity requirement is that it does not require a regulator to observe individual contracts $c_{1}(\theta)$ - only an aggregate portfolio allocation of the intermediaries needs to be observed.

We now intuitively describe the effects that a binding liquidity requirement has on the interest rate on private markets. Let $\hat{c}_{1}(\theta)$ be the allocation of consumption that arises in an equilibrium without government intervention in Definition 3. Suppose that a liquidity floor $i$ is set higher than the amount of aggregate liquidity provided by competitive markets:

$$
i>\hat{\imath},
$$

where $\hat{\imath}=\int \hat{c}_{1}(\theta) d F(\theta)$. When a liquidity floor is imposed, the aggregate endowment in the private markets in the first period $\left(\int c_{1}(\theta) d F(\theta)\right)$ is equal to $i$ rather than $\hat{\imath}$. Recall that private trading markets in which agents participate after receiving their allocation from the intermediaries are an endowment economy. The liquidity floor increases the first period aggregate endowment in the private market (and, correspondingly, decreases the second period endowment) and, therefore, lowers the interest rate $R$ such that $R<\hat{R}$. Imposing a binding liquidity cap has the opposite effect as it lowers the first period aggregate endowment and, therefore, increases $R$ such that $R>\hat{R}$.

The mechanism by which a liquidity requirement affects the interest rate on the private markets is a key to understanding the main idea behind how our model works. In the absence of regulations, it is impossible for the interest rate $R$ on the private market to differ from $\hat{R}$. As we showed in Proposition 2, an intermediary would engage in arbitrage and would not internalize possible adverse effects that such arbitrage has on the provision of incentives and risk-sharing in the economy. The liquidity requirement puts a limit on the minimal (maximal) first period payments (liquidity) an intermediary can make and limits arbitrage by intermediaries.

Why may it be the case that, for example, a decrease in the private market interest rate (that 
corresponds to a binding liquidity floor $i>\hat{\imath}$ ) improves welfare and risk sharing? There are two effects of decreasing the private market interest rate. First, it is clear that a decrease in $R$ below $\hat{R}$ decreases welfare as it introduces an intertemporal wedge in the marginal utilities of agents. There is also a second effect. Recall that unobservability of agents' types and possibility of trades require that agents of various types receive the same present value of consumption evaluated at the private market interest rate $R$ :

$$
c_{1}(\theta)+\frac{c_{2}(\theta)}{R}=c_{1}\left(\theta^{\prime}\right)+\frac{c_{2}\left(\theta^{\prime}\right)}{R} .
$$

For a given level of the present value of consumption, a regulator has a policy instrument - changing the interest rate. Therefore, the amount of resources evaluated at the real rate of return may differ across agents

$$
c_{1}(\theta)+\frac{c_{2}(\theta)}{\hat{R}} \neq c_{1}\left(\theta^{\prime}\right)+\frac{c_{2}\left(\theta^{\prime}\right)}{\hat{R}} .
$$

A change in the interest rate leads to a relative redistribution of resources from the first to the second period which may benefit an agent who derives a higher utility from a given present value of consumption streams and lead to an improvement in the ex-ante welfare. Competitive markets lack this additional instrument because of arbitrage and the fact that each individual firm cannot set the interest rate. A regulator, however, can affect the interest rate and achieve allocations better than autarcic allocations achieved by the markets. We show next how the exact form of the liquidity requirement and a corresponding direction of the private market interest rate change depend on the form of agents' preferences.

\subsection{Optimal liquidity regulations}

We first simplify the problem of characterizing an equilibrium with a liquidity adequacy requirement. Let

$$
V(I, R ; \theta)=\max _{x_{1}, x_{2}} u\left(x_{1}, x_{2} ; \theta\right)
$$

subject to

$$
x_{1}+\frac{x_{2}}{R} \leq I,
$$

be the ex-post indirect utility of an investor of type $\theta$ if her income is $I$, and the interest rate on the private market is $R$. Denote by $x_{1}^{u}(I, R ; \theta)$ and $x_{2}^{u}(I, R ; \theta)$ the uncompensated demand functions in this problem.

It is easy to see that the problem of finding an optimal liquidity requirement is to choose the interest rate $R$ and income $I$ to maximize the expected indirect utility of agents subject to feasibility constraints.

$$
\max _{I, R} \int V(I, R ; \theta) d F(\theta)
$$

subject to

$$
\int\left\{x_{1}^{u}(I, R ; \theta)+\frac{x_{2}^{u}(I, R ; \theta)}{\hat{R}}\right\} d F(\theta) \leq e,
$$


where $I=x_{1}^{u}(I, R ; \theta)+\frac{x_{2}^{u}(I, R ; \theta)}{R}$ is the ex-post market value of allocations. Note that the incentive compatibility that requires an agent not to misrepresent his type and not to engage in the trades on private markets implies that the same net present value of allocations, $I$, evaluated at the interest rate $R$ has to be given to agents of different types $\theta$ as, otherwise, an agent would always prefer to claim a higher income.

We now analyze two key first order conditions that characterize problem (22). Consider the first order condition of this program with respect to income $I$ :

$$
\int\left[V_{I}(I, R ; \theta)-\lambda\left\{x_{1, I}^{u}(I, R ; \theta)+\frac{x_{2, I}^{u}(I, R ; \theta)}{\hat{R}}\right\}\right] d F_{\theta}=0,
$$

and the first order condition for the interest rate $R$ :

$$
\int\left\{V_{R}(I, R ; \theta)-\lambda\left[x_{1, R}^{u}(I, R ; \theta)+\frac{x_{2, R}^{u}(I, R ; \theta)}{\hat{R}}\right]\right\} d F_{\theta}=0,
$$

where we denote by $\lambda$ a multiplier on (23), by $x_{1, I}^{u}$ and $x_{2, I}^{u}$ the derivatives of the uncompensated demands with respect to $I$, and by $x_{1, R}^{u}$ and $x_{2, R}^{u}$ derivatives of uncompensated demands with respect to $R$.

We manipulate these conditions (proof in the appendix) to obtain a characterization of the optimal wedge between the interest rate on the private market and the return on savings.

Proposition 3 (Optimal Wedge) Let $I^{*}$ and $R^{*}$ be solutions to the problem of finding the optimal liquidity adequacy requirement (22). Then $R^{*}$ satisfies

$$
\frac{1}{\hat{R}}-\frac{1}{R^{*}}=\frac{\frac{1}{\lambda} \operatorname{Cov}\left\{V_{I}\left(I^{*}, R^{*} ; \theta\right), \frac{x_{2}^{u}\left(I^{*}, R^{*} ; \theta\right)}{R^{* 2}}\right\}}{\int x_{2, R}^{c}\left(I^{*}, R^{*} ; \theta\right) d F_{\theta}+\operatorname{Cov}\left\{x_{2, I}^{u}\left(I^{*}, R^{*} ; \theta\right), \frac{x_{2}^{u}\left(I^{*}, R^{*} ; \theta\right)}{R^{* 2}}\right\}},
$$

where $x_{2, R}^{c}$ is a compensated demand in problem (22).

Formula (26) characterizes the optimal wedge between the interest rate $R$ and the rate of return on savings $\hat{R}$ in terms of easily interpretable parameters such as indirect utility functions, uncompensated and compensated demands and the properties of the distribution of shocks. This formula also provides intuition for the result that we prove next that relates the form of the shocks that agents experience to the optimal liquidity adequacy requirement.

First, we describe the intuition for the form of the numerator of the wedge in equation (26). Consider first the case of liquidity shocks. The regulator wants to allocate a higher amount of lifetime consumption to agents with a higher lifetime value of income, i.e., to those with lower $\theta$, implying that $V_{I, \theta}\left(I, R^{*} ; \theta\right)<0$. An agent with low $\theta$, for a given level of income $I$, prefers a lower consumption in the second period. The covariance between $V_{I}\left(I, R^{*} ; \theta\right)$ and $x_{2}^{u}\left(I, R^{*} ; \theta\right)$, is, therefore, negative. The intuition for this case is as follows. For a given level of income, a decrease in the interest rate allows agents with low $\theta$ to consume more in the first period and 
yield a higher lifetime value. We show in the Theorem that follows that an interest rate $R^{*}<\hat{R}$ allows the regulator to allocate more resources to agents with higher consumption opportunities. A simpler and less technical intuition is that of controlling a joint deviation: a deviating agent wants to pretend to have lower $\theta$ and then save to consume in period two a larger amount than a truth-telling agent. A decrease in the interest rate, therefore, negatively affects a deviating agent more than a truth-telling agent and relaxes incentive constraints.

The interpretation of the numerator in (26) for the case of discount shocks is similar. The planner's value of income is higher for agents with a higher $\theta$ who prefer to consume their endowment in the second period, therefore, the covariance in the numerator is positive. The intuition for this case is as follows. For a given level of income, an increase in the interest rate allows agents with high $\theta$ to consume more in the second period and yield a higher lifetime value. We show in the Theorem that follows that an interest rate $R^{*}>\hat{R}$, therefore, allows the regulator to allocate more resources to agents with better consumption opportunities. As in the case of liquidity shocks a simpler intuition is that of controlling a joint deviation: a deviating agent wants to pretend to have higher $\theta$ and then borrow to consume in period two a larger amount than a truth-telling agent. An increase in the interest rate, therefore, negatively affects a deviating agent more than a truth-telling agent and relaxes incentive constraints.

For the case of the valuation-neutral preferences the intuition is simple, as, at the optimum with observable consumption, agents do not want to retrade, hence, the optimum with and without unobservable consumptions coincide.

Now we turn our attention to the denominator of $(26)$. It is clear that $x_{2, R}^{c}(I, R ; \theta)>0$ - a standard property of compensated demand functions. However, the sign of $\operatorname{Cov}\left\{x_{2, I}^{u}(I, R ; \theta), \frac{x_{2}^{u}(I, R ; \theta)}{R^{2}}\right\}$ is a priori indeterminate, even under the assumption that $V_{I}(I, R ; \theta)>0$ or $V_{I, \theta}(I, R ; \theta)<0$. Moreover, the sign of the denominator

$$
\int x_{2, R}^{c}(I, R ; \theta) d F_{\theta}+\operatorname{Cov}\left\{x_{2, I}^{u}(I, R ; \theta), \frac{x_{2}^{u}(I, R ; \theta)}{R^{2}}\right\}
$$

is also indeterminate. We now make an assumption that allows us determine the sign of the wedge in (26) and then show this assumption holds in two natural cases.

Assumption 2. For all $(I, R)$,

$$
\int x_{2, R}^{c}(I, R ; \theta) d F_{\theta}+\operatorname{Cov}\left\{x_{2, I}^{u}(I, R ; \theta), \frac{x_{2}^{u}(I, R ; \theta)}{R^{2}}\right\}>0 .
$$

The lemma that follows shows two natural cases in which Assumption 2 holds.

Lemma 2 Assumption 2 holds under the conditions that follow.

1. Preferences are homothetic. 
2. The variance of the shocks is small. Consider a family of distributions $\left\{F^{\gamma}\right\}$ indexed by $1 \geq \gamma \geq 0$ with support in $\left[\theta_{L}, \theta_{H}\right]$. Suppose that $F^{\gamma}(\theta, z)$ is continuous in $(\theta, \gamma)$. Suppose that $\lim _{\gamma \rightarrow 0} \sigma_{F \gamma}=0$ where $\sigma_{F^{\gamma}}$ is the variance of $F^{\gamma}$. Then there exists $1>\bar{\gamma}>0$ such that for all $\bar{\gamma} \geq \gamma \geq 0$, assumption 2 holds.

Proof. In the appendix.

Now we use Assumption 2 and Proposition 3 to derive a theorem that characterizes the optimal liquidity adequacy requirement.

Theorem 1 (Optimal liquidity adequacy requirements) Let $R^{*}$ be the interest rate associated with the optimal liquidity requirement, i.e, a solution to (22). Suppose Assumption 2 holds. Let $C_{1}^{C E}=\int c_{1}(\theta) d F(\theta)$ be the amount of liquidity (first period consumption) provided in the competitive equilibrium $C E^{3}$ in Definition 3, and let $C_{1}^{*}=\int c_{1}^{*}(\theta) d F(\theta)$ be the amount of liquidity (first period consumption) provided in the solution to the problem of finding the optimal liquidity adequacy requirement defined in (22).

1. If preferences are of the discount shock form as in example $1, R^{*}-\hat{R}>0$. The optimal liquidity requirement is a liquidity cap, and competitive markets are inefficient. Markets overprovide liquidity, $C_{1}^{C E}>C_{1}^{*}$.

2. If preferences are of liquidity shock form as in example $2, R^{*}-\hat{R}<0$. The optimal liquidity requirement is a liquidity floor, and competitive markets are inefficient. Markets underprovide liquidity, $C_{1}^{C E}<C_{1}^{*}$.

3. If preferences are valuation-neutral shocks, then $R^{*}=\hat{R}$. No regulations are needed. Moreover, the solution to the optimal problem $S P^{2}$ without private markets, solution to the problem of the optimal liquidity adequacy requirement (22), and the solution to the competitive equilibrium with private markets $C E^{3}$ coincide.

Proof. In the appendix.

Theorem 1 is one of the central results of the paper and provides a characterization of the optimal liquidity adequacy requirement and the associated interest rate on the private markets depending on the nature of the shocks (liquidity or discount factor shocks) that agents experience. The theorem states the form of the optimal liquidity requirement and shows that competitive markets for liquidity are inefficient. Importantly, we show that whether markets provide too little liquidity and too much investment in the long asset (as in the case of liquidity shocks) or too much liquidity and too little investment in the long asset (as in the case of discount shocks) depends on the structure of the environment, specifically, on the form of shocks affecting agents.

The technical reason for the failure of the welfare theorem that we proved in Theorem 1 is an externality that each financial intermediary faces. When intermediaries allocate consumption 
to agents, they do not take into account how such allocations affect interest rates on the private market. We can see that the interest rate enters the production set of each intermediaries in equation (14). An imposition of a liquidity regulation and a corresponding change in the private market interest rate partially corrects such externality and leads to improvement in welfare. This externality can be called a "pecuniary externality" as it operates through price (interest rate) on the private markets. The reason why such an externality has effects on the welfare is because our environment is that of private information. ${ }^{10}$

\subsection{Optimal liquidity adequacy requirements implements the social optimum with retrading $S P^{3}$}

A natural question arises after reading the previous section whether the optimal liquidity adequacy requirement is the best regulation within a particular class of regulations (i.e., within the class of liquidity adequacy requirements). It may be the case that there exists another, perhaps more complicated, regulation scheme that achieves superior allocations given constraints imposed by unobservability of types and possibility of hidden trades. In this section, we show that a competitive equilibrium with optimal liquidity requirement implements the constrained efficiency that we call $S P^{3}$, i.e., achieves the highest possible welfare given these two informational frictions.

We first formally define the constrained efficient problem $S P^{3}$. Consider a social planner that cannot observe or shut down trades on private markets and cannot observe agents' types. The difference with the problem $S P^{2}$ is that, in addition to the private information faced by $S P^{2}$, planner $S P^{3}$ faces constraints that agents may trade on the private market. The social planner $S P^{3}$ chooses the allocations $\left\{c_{1}(\theta), c_{2}(\theta)\right\}$ that maximize the ex ante utility of consumers. The revelation principle shows that, without loss of generality, the social planner can offer a contract $\left\{c_{1}(\theta), c_{2}(\theta)\right\}$ so that all consumers choose to report their types truthfully to the planner and do not trade on the private market. It is easy to show that the social planner can affect the return on trades among agents by allocating different amount of aggregate consumption across time.

A constrained efficient allocation $\left\{c_{1}(\theta), c_{2}(\theta)\right\}$ is the solution to the problem $S P^{3}$ given by:

$$
\max _{c_{1}(\theta), c_{2}(\theta)} \int u\left(c_{1}(\theta), c_{2}(\theta) ; \theta\right) d F(\theta)
$$

s.t.

$$
\begin{gathered}
\int\left(c_{1}(\theta)+c_{2}(\theta) / \hat{R}\right) d F(\theta) \leq e, \\
u\left(c_{1}(\theta), c_{2}(\theta) ; \theta\right) \geq \tilde{V}\left(\left\{c_{1}(\theta), c_{2}(\theta)\right\}, R ; \theta\right),
\end{gathered}
$$

where $R$ is the equilibrium interest rate on the private market, given the profile of endowments $\left\{c_{1}(\theta), c_{2}(\theta)\right\}$.

\footnotetext{
${ }^{10}$ Allen and Gale (2004) results of whether intermediaries underprovide or overprovide liquidity compared to the optimum depends on the degree of risk aversion of consumers. Our result on private intermediaries underproviding or overproviding liquidity does not depend on the degree of risk aversion and depends only on the structure of shocks.
} 
It is important to note two features of the incentive compatibility constraint (30). First, it is at least as tight as the constraint with observable consumption (6). The reason is that the planner has to ensure that, in addition to truthful revelation of types, consumers do not engage in trades on the private markets. Second, the right hand side of the incentive compatibility constraint depends on the whole vector of endowments $\left\{c_{1}(\theta), c_{2}(\theta)\right\}$ for all consumers in the economy, not just for the individual consumer $\theta$. We showed that the interest rate actually depends on the relative amount of aggregate consumption provided by the planner in the first period versus the aggregate amount of consumption provided in the second period.

We now show that the optimal liquidity adequacy requirement is the best regulation that can be achieved given the informational frictions of unobservability of types and trades among agents. The theorem that follows proves that our focus on just one class of regulations - liquidity adequacy requirements - is not restrictive.

Theorem 2 (Optimal liquidity requirement is efficient) The optimal liquidity adequacy requirement implements the constrained efficient allocation which solves $S P^{3}$, i.e. solutions to problems (22) and (28) coincide.

Proof. In the appendix.

Another important implication of this theorem is to provide comparison with previous results derived in the environments with optimal taxation and private markets. An abstract treatment of a related problem is given in Bisin, et.al. (2001) who show that, in a general class of environments with anonymous markets, taxes can achieve Pareto improvement. The difference with our setup is that they do not define the constrained efficient problem $S P^{3}$ but rather show that a local linear tax can improve upon the market allocation. Golosov and Tsyvinski (2007) study a dynamic model of optimal taxation and do define the optimal program similar to our $S P^{3}$. They also show that a linear tax on savings locally improves upon the competitive equilibrium allocation. In their model, in fact, it can be shown that a linear tax (locally optimal policy intervention) would not implement the problem $S P^{3}$. The question of the implementation of the problem $S P^{3}$ in that model, or more generally in a dynamic Mirrlees model with private trades, is still an open question. In our paper, in contrast with Bisin, et.al. (2001) and with Golosov and Tsyvinski (2007) we find the optimal, rather than locally improving regulation. As we show below on the two important special cases that we solve analytically, the welfare gain of finding the optimal regulation may be significant.

\subsection{Two closed-form examples}

The results derived in Theorem 1 provide a general characterization of the form of optimal liquidity requirement depending on the form of the preferences. In this section we consider two cases for which we derive a closed form characterization of the optimum that further characterizes the optimal liquidity requirement in terms of underlying parameters. The first case is an example in which the utility of consumption is logarithmic. The second case is an environment of Diamond and Dybvig (1983). 


\subsubsection{Log case}

We further extend Proposition 3 and Theorem 1 by providing a closed form solution for the case of a logarithmic utility function. The reason why logarithmic utility allows a closed form solution is because wealth and substitution effects of changing an interest rates cancel, and formulas for compensated and uncompensated demands, indirect utility functions and their derivatives have an easy algebraic form. With a more general utility function, equation (26) that provides an optimal wedge between $R$ and $R^{*}$ becomes more complicated and does not allow a closed form solution.

Assume preferences are of a form nesting those in examples 1, 2 and 3 :

$$
u\left(x_{1}, x_{2} ; \theta\right)=\theta_{1} \log \left(x_{1}\right)+\theta_{2} \log \left(x_{2}\right),
$$

with $\theta=\left(\theta_{1}, \theta_{2}\right)$. Specifically, for the case of discount shocks $\theta_{1}=1, \theta_{2}=\theta$; for the case of liquidity shocks $\theta_{1}=1 / \theta, \theta_{2}=1$; f for the case of valuation-neutral shocks $\theta_{1}=1-\theta, \theta_{2}=\theta$.

We leave the algebraic manipulations to the appendix and derive the following proposition.

Proposition 4 (Closed form solution for the logarithmic case) Assume that $\hat{u}=\log (c)$. Then the optimal liquidity requirement $i^{*}$ and the interest rate $R^{*}$ associated with it are given as follows.

1. Suppose preferences are discount factor shocks. The liquidity requirement is a liquidity cap.

Moreover,

$$
\frac{R^{*}}{\hat{R}}=1-\frac{\operatorname{Cov}\left\{\theta,(1+\theta)^{-1}\right\}}{\int \theta(1+\theta)^{-1} d F_{\theta}}>1, \text { and } i^{*}=\frac{e \int(1+\theta)^{-1} d F_{\theta}}{\int\left\{(1+\theta)^{-1}+\theta(1+\theta)^{-1} R^{*} / \hat{R}\right\} d F_{\theta}} .
$$

2. Suppose preferences are liquidity shocks. The liquidity requirement is a liquidity floor. Moreover,

$$
\frac{R^{*}}{\hat{R}}=1+\frac{\operatorname{Cov}\left\{\theta^{-1}, \theta(1+\theta)^{-1}\right\}}{\int \theta^{-1} d F_{\theta} \int \theta(1+\theta)^{-1} d F_{\theta}}<1, \text { and } i^{*}=\frac{e \int(1+\theta)^{-1} d F_{\theta}}{\int\left\{(1+\theta)^{-1}+\theta(1+\theta)^{-1} R^{*} / \hat{R}\right\} d F_{\theta}} .
$$

3. If preferences are value neutral, $R^{*}=\hat{R}$.

This proposition is important as it gives a complete closed form solution to the problem of finding an optimal liquidity adequacy requirement. The interpretation of the solution is also simple. Consider the formulas for $R^{*}$ for either the case of liquidity shocks of discount shocks. In the absence of the second term, in these formulas the interest rate $R^{*}=\hat{R}$. This second term measures the value of the distortion introduced by private information and trades in the financial markets and depends on the form of preferences and the distribution of shocks.

We also derived a closed form solution for the welfare gain of imposing the optimal liquidity adequacy requirement as a Corollary to the Proposition above. 
Corollary 1 (Welfare gain of optimal liquidity adequacy requirement). If the utility function is logarithmic, the welfare gain of imposing optimal liquidity requirement, i.e., the difference in ex-ante utility between the solutions to problem $S P^{3}$ and $C E^{3}$ is given as follows.

In the liquidity shocks model

$$
\Delta=\int\left[-(\theta+1) \log \left(1-\left(1-\frac{R^{*}}{\hat{R}} \frac{1}{1+\theta}\right)\right)+\log \left(1-\left(1-\frac{R^{*}}{\hat{R}}\right)\right)\right] d F(\theta) .
$$

In the discount shocks model

$$
\Delta=\int\left[-(\theta+1) \log \left(1+\left(\frac{R^{*}}{\hat{R}}-1\right) \frac{\theta}{1+\theta}\right)+\theta \log \left(1+\left(\frac{R^{*}}{\hat{R}}-1\right)\right)\right] d F(\theta)
$$

Calculations such as the one above stress importance of finding optimal rather than locally improving regulations as the optimum can lead to significant welfare gain $\Delta$.

\subsubsection{Diamond-Dybvig preferences}

In this section we provide a closed form solution to the optimal problem of finding the optimal liquidity adequacy requirement for the setup considered by Diamond and Dybvig (1983) and Jacklin (1987). This environment is widely used in the literature on the financial intermediation. These preferences are, however, special as the unconstrained solution (without private information) coincides with the solution to the optimum with private information about agent's types but without private markets. In our notation, the solutions to $S P^{1}$ and $S P^{2}$ are identical. Jacklin (1987) showed that when agents can freely engage in trades the competitive market allocation features no risk sharing and has interest rate on the private market $R$ equal to $\hat{R}$ - this is analogue of our Proposition 2 for the environment we considered. Jacklin (1987) and Allen and Gale (2004) conclude that it is impossible to achieve any allocation other than the autarky. The new result that we present here is that, for the case of the Diamond-Dybvig preferences, liquidity regulations can improve upon competitive market allocation and, in fact, the solution with optimal liquidity adequacy requirement coincides with the unconstrained allocation, $S P^{1}$. We present an analytical solution for such optimal regulation, the liquidity floor, and for the interest rate on the private market associated with it.

Suppose there are two type of agents denoted by $\theta \in\{0,1\}$. Let $\pi$ be the fraction of agents of type $\theta=0$. Preferences for agent of type $\theta$ are given by

$$
U\left(c_{1}, c_{2}, \theta\right)=(1-\theta) u\left(c_{1}\right)+\theta \rho u\left(c_{1}+c_{2}\right),
$$

where $u$ is twice continuously differentiable, increasing, strictly concave, and satisfies Inada conditions $u^{\prime}(0)=+\infty$ and $u^{\prime}(+\infty)=0$. Also, we assume as in Diamond and Dybvig (1983) that the 
coefficient of relative risk aversion is everywhere greater than 1

$$
\frac{-c u^{\prime \prime}(c)}{u^{\prime}(c)} \geq 1 \text { for all } c \geq 0
$$

We start with the analysis of the benchmark problem in which there are no private markets analogously to Section 4. It is easy to show that as in Proposition 1 the competitive equilibrium allocation implements the constrained efficient allocation without private markets. The constrained efficient allocation $S P^{2}$ solves the following problem:

$$
\max \pi u\left(c_{1}(0)\right)+(1-\pi) \rho u\left(c_{1}(1)+c_{2}(1)\right)
$$

s.t.

$$
\begin{gathered}
\pi\left(c_{1}(0)+\frac{c_{2}(0)}{\hat{R}}\right)+(1-\pi)\left(c_{1}(1)+\frac{c_{2}(1)}{\hat{R}}\right) \leq e, \\
u\left(c_{1}(0)\right) \geq u\left(c_{1}(1)\right), \\
u\left(c_{1}(1)+c_{2}(1)\right) \geq u\left(c_{1}(0)+c_{2}(0)\right) .
\end{gathered}
$$

As noted by Diamond and Dybvig (1983), the incentive compatibility constraints are not binding at the optimum, so that the unconstrained allocation is attained, i.e., the allocation that we call $S P^{1}$ in which there is no private information, and incentive compatibility constraints (33) and (34) are omitted. In other words, solutions to problems $S P^{1}$ and $S P^{2}$ coincide. This allocation is characterized by

$$
\begin{gathered}
c_{2}(0)=c_{1}(1)=0, \\
\rho \hat{R} u^{\prime}\left(c_{2}(1)\right)=u^{\prime}\left(c_{1}(0)\right), \\
\pi c_{1}(0)+(1-\pi) \frac{c_{2}(1)}{\hat{R}}=e .
\end{gathered}
$$

To verify that this allocation satisfies incentive compatibility, we need only check that $c_{2}(1) \geq c_{1}(0)$, which follows from $\rho \hat{R}>1$.

Now we turn to the analysis of the effects of private markets that is similar to our Section 5 . First, consider competitive equilibrium with private markets. Reasoning paralleling that in the Proposition 2 shows that the equilibrium interest rate on the private markets is equal to $\hat{R}$ and that no risk sharing is achieved: agents's present value of consumption evaluated at the interest rate $\hat{R}$ is equated across different types. This is a result shown by Jacklin (1987).

We show that optimal liquidity requirement allows to change the interest rate on the private market, implements the optimal program $S P^{3}$ which in turns coincides with the unconstrained optimum $S P^{1}$ and with constrained efficient allocation with private types but no hidden trades. The analysis closely follows Section 6.2 and proofs of Proposition 3 and Theorem 1 . In the appendix, we provide the algebra that gives the closed form solution for the optimal interest rate $R^{*}$ as a solution to the following equation: 


$$
\frac{u^{\prime}\left(\frac{e}{\pi+(1-\pi) \frac{R}{\hat{R}}}\right)}{u^{\prime}\left(\frac{R e}{\pi+(1-\pi) \frac{R}{\hat{R}}}\right)}-\rho \hat{R}=0
$$

We can implement the solution with a floor $i^{*}$ on the holdings of short term assets given by

$$
i^{*}=\frac{e}{\pi+(1-\pi) \frac{R^{*}}{\hat{R}}} .
$$

Moreover, in the case $u(c)=\log (c)$, we have $R=\rho \hat{R}$. We collect the results of this section in the following proposition.

Proposition 5 (Closed form solution for the Diamond-Dybvig case) Consider the setup of Diamond and Dybvig (1983).

1. The equilibrium interest rate on the private market is $R^{c e}=\hat{R}$. Competitive market allocations with private markets are inefficient. Markets underprovide liquidity.

2. Optimal liquidity floor $i^{*}$, given by (39), implements the optimal unconstrained allocation $S P^{1}$.

(a) The interest rate associated with such optimal liquidity regulation is given by (38).

(b) If the utility function is logarithmic, then the interest rate associated with the optimal liquidity regulation is given by $R^{*}=\rho \hat{R}$.

Proof. In the appendix.

The intuition behind this proposition highlights the key forces behind our model. Consider the case of logarithmic utility. In the competitive market, the only possible equilibrium interest rate on the private market is $R=\hat{R}$ as each individual financial intermediary would engage in arbitrage if $R$ were different from $\hat{R}$. The competitive equilibrium allows no risk sharing as the possibility of engaging in trades on financial markets leads to equalization of incomes $I$ of agents of different types, and these incomes are evaluated with the interest rate $\hat{R}$. Now consider how the competitive market allocation can be improved. Imposing a liquidity floor increases the amount of first-period endowment on the private market and decreases the interest rate $R<\hat{R}$. This relaxes incentive compatibility constraints. A short, nontechnical intuition is as follows. Consider a possible deviation in this model: an agent of type 1 can claim to be an agent of type 0 and then save to consume in the second period. At the interest rate $R=\rho \hat{R}$, an agent of type 1 does not find it profitable to engage in such deviation. ${ }^{11}$

It is easy to calculate the welfare gain of imposing the optimal liquidity adequacy requirement.

\footnotetext{
${ }^{11}$ Caballero and Krishanmurthy (2003) and Lorenzoni (2006) derive a similar result in their environment.
} 
Corollary 2 (Welfare gain of optimal liquidity adequacy requirement). Consider the setup of Diamond and Dybvig (1983). If the utility function is logarithmic, the welfare gain of imposing optimal liquidity requirement, i.e., the difference in ex-ante utility between the solutions to problem $S P^{3}$ and $C E^{3}$, is given by

$$
\Delta=\pi \log \left(\frac{1}{\pi+(1-\pi) \rho}\right)+(1-\pi) \rho \log \left(\frac{\rho}{\pi+(1-\pi) \rho}\right) .
$$

This corollary again stresses the importance of studying optimal rather than local liquidity adequacy requirements as potential welfare gains can be quite large.

\section{Extensions}

In this section we consider three extensions of the model described above: introducing aggregate shocks, modelling an environment with idiosyncratic shocks to financial intermediaries, and considering direct access to intertemporal technology by agents.

\subsection{Aggregate shocks}

It is easy to extend the model to the case in which the economy experiences aggregate shocks to $e$ and $\hat{R}$ that are known in period $t=0$. Suppose that there are $N$ aggregate states $\eta=\{1,2, . ., N\}$ and the state is observable. We denote the probability of these states occurring as $\mu(\eta)$. We notice that it is technologically impossible for the society to transfer resources across aggregate states. Therefore, the problem with aggregate shocks can be reduced to solving $N$ independent problems described in case without aggregate shocks and is, essentially, a comparative statics exercise.

The case of the logarithmic utility is again the simplest case that allows us to completely characterize the solution. Consider equations (64) and (65). An aggregate shock either to endowment $e$ or to the return $\hat{R}$ can be studied as comparative statics with respect to $e$ and $\hat{R}$.

We can easily see that for the case of the aggregate endowment shocks, the interest rate on the private market does not depend on the realization of the aggregate shock $-R^{*}(\eta)$ is constant. Let's define by liquidity requirement in a ratio form, $i_{r}(\eta)$, a constraint on a problem of a competitive firm that stipulates either a maximal or minimal proportion of the total assets invested in a short asset $\left(\int c_{1}(\theta) d F(\theta)\right) / e$ for the realization of the aggregate shock $\eta$, and $R^{*}(\eta)$ define corresponding interest rate on the private market. Then $i_{r}^{*}(\eta)$ is constant for all $\eta$. In fact, it is easy to show that

this result also holds for the utility $\hat{u}(c)=\frac{c^{1-\sigma}-1}{1-\sigma}$. The case of the shocks to the rate of return is equally simple. It is easy to show that $i_{r}^{*}(\eta)$ and $R^{*}(\eta) / \hat{R}(\eta)$ are constant for all $\eta$.

\subsection{Idiosyncratic shocks to intermediaries and interbank markets}

In this section we discuss an extension of the model to the case in which intermediaries experience idiosyncratic observable shocks. We show that if there are complete interbank markets then this 
model reduces to the case described in previous sections in which all intermediaries are identical. The intuition for this result is simple: in period 0, intermediaries can trade bonds with the payoff contingent on the shocks realized in period 1 . We illustrate the result on the case without aggregate uncertainty in which intermediaries face return shocks.

Formally, we proceed as follows. At time $t=1$, an intermediary can face a rate of return shock $n \in\{1, \ldots, N\}$ with probability $\eta^{n}$ under which the return on the long asset is $\hat{R}(n)$. We assume that there is no aggregate uncertainty and that

$$
\begin{gathered}
\sum_{n} \eta^{n} \hat{R}(i)=\hat{R}, \\
\sum_{n} \eta^{n}=1 .
\end{gathered}
$$

At time 0 there are interbank markets in which intermediaries trade $N$ Arrow securities. The price of each security is $q^{n}$. The security pays 1 if state $n$ occurs and 0 otherwise. Prices $q^{n}$ are determined by a market clearing condition. It is immediate to see that intermediaries choose to fully insure themselves at $t=0$ against idiosyncratic shocks. The problem of each intermediary then reduces to the case of no idiosyncratic shocks described above.

\subsection{Direct access to technology}

Another variation of our setup would be the case in which some agents have access to technology that yields $\hat{R}$ directly without the need for financial intermediaries while other agents need an intermediary to access the technology. If we modified our assumption that all activities at the intermediary level is observable and instead supposed that a regulator could observe aggregate amount of investment in the technology yielding $\hat{R}$, then our results would also hold. The constrained optimum in that model would be implemented by a linear tax on returns to investment of those who can access the technology and by liquidity adequacy requirement on the financial intermediaries serving liquidity needs of agents who can not access the technology.

\section{Conclusion}

In this paper we provided a novel theoretical mechanism how manipulation of aggregate liquidity via regulation of financial intermediaries in the presence of markets can provide risk sharing while competitive markets reach only autarcic allocations. A change in the interest rate on the private markets that is generated by a liquidity requirement can be used as an instrument to improve ex-ante welfare when agents have unobservable types and can trade in private markets. Moreover, the best liquidity adequacy requirement is the best regulation as it implements the constrained efficient allocation subject to unobservable types and hidden trades. We provided a tight analytical characterization of the problem of the optimal liquidity requirement and the optimal wedge between the interest rate on the private market and the rate of marginal rate of transformation. A liquidity 
requirement is a simple tool that can be used by policymakers to regulate liquidity provision. Depending on the types of shocks, liquidity or discount shocks, that agents or firms in the economy experience, we provide conditions under which the regulator should use either a liquidity cap or a liquidity floor. Importantly, for a general specification of preferences, we derived a characterization of the form of the optimal liquidity requirement and also provided closed form solutions for two important cases.

\section{Appendix}

\subsection{Proof of Proposition 1}

Because of the single crossing condition in Assumption 1, we can rewrite the problem (7) in the following form:

$$
\max \int u(c(\theta) ; \theta) d F(\theta)
$$

subject to

$$
\begin{gathered}
u(c(\theta) ; \theta)=\int_{\theta_{L}}^{\theta} u_{\theta^{\prime}}\left(c\left(\theta^{\prime}\right) ; \theta^{\prime}\right) d \theta^{\prime}+u\left(c\left(\theta_{L}\right) ; \theta_{L}\right), \\
\frac{d c_{2}(\theta)}{d \theta} \geq 0 \\
\int\left[c_{1}(\theta)+\frac{c_{2}(\theta)}{\hat{R}}\right] d F(\theta) \leq e .
\end{gathered}
$$

We assume that there is no bunching and drop constraint (42). In problem (40), attach multipliers $\mu_{\theta}$ to (41), $\lambda$ to (43) and form the following Lagrangian:

$$
\begin{aligned}
L= & \int\left\{u(c(\theta) ; \theta)+\lambda\left[e-c_{1}(\theta)-\frac{c_{2}(\theta)}{\hat{R}}\right]\right\} d F_{\theta} \\
& +\int\left\{u(c(\theta) ; \theta)-u\left(c\left(\theta_{L}\right) ; \theta_{L}\right)-\int_{\theta_{L}}^{\theta} u_{\theta}\left(c\left(\theta^{\prime}\right) ; \theta^{\prime}\right) d \theta^{\prime}\right\} \mu_{\theta} d F_{\theta} .
\end{aligned}
$$

Integrating by parts we can rewrite (44) as

$$
\begin{aligned}
L= & \int\left\{u(c(\theta) ; \theta)+\lambda\left[e-c_{1}(\theta)-\frac{c_{2}(\theta)}{\hat{R}}\right]\right\} d F_{\theta} \\
& +\int\left\{u(c(\theta) ; \theta)-u\left(c\left(\theta_{L}\right) ; \theta_{L}\right)\right\} \mu_{\theta} d F_{\theta}-\int u_{\theta}(c(\theta) ; \theta) \frac{\int_{\theta}^{\theta_{H}} \mu_{\theta^{\prime}} d F_{\theta^{\prime}}}{f_{\theta}} d F_{\theta} .
\end{aligned}
$$

The first order conditions for $c_{1}(\theta)$ and $c_{2}(\theta)$ are

$$
\begin{gathered}
u_{c_{1}}(c(\theta) ; \theta)-\lambda+\mu_{\theta} u_{c_{1}}(c(\theta) ; \theta)-\frac{u_{\theta, c_{1}}(c(\theta) ; \theta) \int_{\theta}^{\theta} \mu_{\theta^{\prime}} d F_{\theta^{\prime}}}{f_{\theta}}=0 \\
u_{c_{2}}(c(\theta) ; \theta)-\frac{\lambda}{\hat{R}}+\mu_{\theta} u_{c_{2}}(c(\theta) ; \theta)-\frac{u_{\theta, c_{2}}(c(\theta) ; \theta) \int_{\theta}^{\theta} \mu_{\theta^{\prime}} d F_{\theta^{\prime}}}{f_{\theta}}=0 .
\end{gathered}
$$


Combining (45) and (46), we find

$$
\frac{u_{c_{2}}(c(\theta) ; \theta) \hat{R}}{u_{c_{1}}(c(\theta) ; \theta)}=\frac{1-\frac{u_{\theta, c_{1}}(c(\theta) ; \theta)}{u_{c_{1}}(c(\theta) ; \theta)} \frac{\int_{\theta}^{\theta} H \mu_{\theta^{\prime}} d F_{\theta^{\prime}}}{\left(1+\mu_{\theta}\right) f_{\theta}}}{1-\frac{u_{\theta, c_{2}}(c(\theta) ; \theta)}{u_{c_{2}}(c(\theta) ; \theta)} \frac{\int_{\theta}^{\theta} H \mu_{\theta^{\prime}} d F_{\theta^{\prime}}}{\left(1+\mu_{\theta}\right) f_{\theta}}}
$$

Assumption 1 implies that

$$
\begin{gathered}
\frac{\partial}{\partial \theta}\left(\frac{\partial u / \partial c_{2}}{\partial u / \partial c_{1}}\right)=\frac{u_{c_{2}, \theta} u_{c_{1}}-u_{c_{1}, \theta} u_{c_{2}}}{u_{c_{1}}^{2}}>0 \\
\frac{u_{\theta, c_{2}}}{u_{c_{2}}}>\frac{u_{\theta, c_{1}}}{u_{c_{1}}}
\end{gathered}
$$

Therefore,

$$
\frac{u_{c_{2}}(c(\theta) ; \theta)}{u_{c_{1}}(c(\theta) ; \theta)}-\frac{1}{\hat{R}} \gtrless 0
$$

if and only if

$$
\frac{\int_{\theta}^{\theta_{H}} \mu_{\theta^{\prime}} d F_{\theta^{\prime}}}{\left(1+\mu_{\theta}\right) f_{\theta}} \gtrless 0
$$

Economically, condition $\frac{\int_{\theta}^{\theta} \mu_{\theta^{\prime}} d F_{\theta^{\prime}}}{\left(1+\mu_{\theta}\right) f_{\theta}}>0$ means that incentive constraints bind downward at $\theta$, while $\frac{\int_{\theta}^{\theta} H \mu_{\theta^{\prime}} d F_{\theta^{\prime}}}{\left(1+\mu_{\theta}\right) f_{\theta}}<0$ means that they bind upward. It is straightforward to show that incentive constraints in (40) bind upward if preferences are as in example 1, and downward if preferences are as in example 2. It is also easy to check that the incentive compatibility constraint does not bind for the value neutral preferences.

\subsection{Some properties of problem (20) used in the proofs}

Denote by $\psi$ the Lagrange multiplier on (21). The envelope theorem implies that:

$$
\begin{gathered}
V_{I}(I, R ; \theta)=\psi, \\
V_{R}(I, R ; \theta)=\frac{\psi x_{2}^{u}(I, R ; \theta)}{R^{2}} .
\end{gathered}
$$

Combining two of the above equations we get:

$$
V_{R}(I, R ; \theta)=\frac{V_{I}(I, R ; \theta) x_{2}^{u}(I, R ; \theta)}{R^{2}} .
$$

Differentiating the budget constraint (21) with respect to income $I$ we obtain:

$$
x_{1, I}^{u}(I, R ; \theta)+\frac{x_{2, I}^{u}(I, R ; \theta)}{R}=1,
$$


or after rearranging

$$
x_{1, I}^{u}(I, R ; \theta)=1-\frac{x_{2, I}^{u}(I, R ; \theta)}{R} .
$$

Analogously, we obtain

$$
x_{1, R}^{u}(I, R ; \theta)+\frac{x_{2, R}^{u}(I, R ; \theta)}{R}-\frac{x_{2, R}^{u}(I, R ; \theta)}{R^{2}}=0 .
$$

\subsection{Proof of Proposition 3}

We can re-express (25) using (49) and (52) as

$$
\int\left\{\frac{x_{2}^{u}(I, R ; \theta)}{R^{2}}\left(V_{I}(I, R ; \theta)-\lambda\right)-\lambda \frac{x_{2, R}^{u}(I, R ; \theta)}{R}\left(\frac{R}{\hat{R}}-1\right)\right\} d F=0 .
$$

Rewrite (53) to obtain

$$
\frac{R}{\hat{R}}-1=\frac{\frac{1}{R} \int\left\{V_{I}(I, R ; \theta)-\lambda\right\} x_{2}^{u}(I, R ; \theta) d F_{\theta}}{\int\left\{\lambda x_{2, R}^{u}(I, R ; \theta)\right\} d F_{\theta}}
$$

Rewrite (24) to obtain

$$
\frac{\int\left(V_{I}(I, R ; \theta)-\lambda\right) d F_{\theta}}{\lambda \int x_{2, I}^{u}(I, R ; \theta) d F_{\theta}}=\left[\frac{1}{\hat{R}}-\frac{1}{R}\right]
$$

Combine (54) and (55)

$$
\frac{\frac{1}{R} \int\left\{V_{I}(I, R ; \theta)-\lambda\right\} x_{2}^{u}(I, R ; \theta) d F_{\theta}}{\int\left\{\lambda x_{2, R}^{u}(I, R ; \theta)\right\} d F_{\theta}}=\frac{R \int\left\{V_{I}(I, R ; \theta)-\lambda\right\} d F_{\theta}}{\lambda \int\left\{x_{2, I}^{u}(I, R ; \theta)\right\} d F_{\theta}} .
$$

Hence, $\int\left\{V_{I}(I, R ; \theta)-\lambda\right\} d F_{\theta}$ is equal to

$$
\int\left\{V_{I}(I, R ; \theta)-\lambda\right\} \frac{x_{2}^{u}(I, R ; \theta)}{R^{2}} d F_{\theta} \frac{\int\left\{x_{2, I}^{u}(I, R ; \theta)\right\} d F_{\theta}}{\int\left\{x_{2, R}^{u}(I, R ; \theta)\right\} d F_{\theta}} .
$$

which can be rearranged as

$$
\begin{aligned}
& \frac{\operatorname{Cov}\left\{V_{I}(I, R ; \theta), \frac{x_{2}^{u}(I, R ; \theta)}{R^{2}}\right\} \frac{\int\left\{x_{2, I}^{u}(I, R ; \theta)\right\} d F_{\theta}}{\int\left\{x_{2, R}^{u}(I, R ; \theta)\right\} d F_{\theta}}}{1-\int \frac{x_{2}^{u}(I, R ; \theta)}{R^{2}} d F_{\theta} \frac{\int\left\{x_{2, I}^{u}(I, R ; \theta)\right\} d F_{\theta}}{\int\left\{x_{2, R}^{u}(I, R ; \theta)\right\} d F_{\theta}}} \\
= & \frac{\operatorname{Cov}\left\{V_{I}(I, R ; \theta), \frac{x_{2}^{u}(I, R ; \theta)}{R^{2}}\right\} \int\left\{x_{2, I}^{u}(I, R ; \theta)\right\} d F_{\theta}}{\int\left\{x_{2, R}^{u}(I, R ; \theta)\right\} d F_{\theta}-\int \frac{x_{2}^{u}(I, R ; \theta)}{R^{2}} d F_{\theta} \int\left\{x_{2, I}^{u}(I, R ; \theta)\right\} d F_{\theta}} .
\end{aligned}
$$


Hence $\int\left\{V_{I}(I, R ; \theta)-\lambda\right\} d F_{\theta}$ is equal to

$$
\frac{\operatorname{Cov}\left\{V_{I}(I, R ; \theta), \frac{x_{2}^{u}(I, R ; \theta)}{R^{2}}\right\} \int\left\{x_{2, I}^{u}(I, R ; \theta)\right\} d F_{\theta}}{\int\left\{x_{2, R}^{u}(I, R ; \theta)\right\} d F_{\theta}-\int \frac{x_{2}^{u}(I, R ; \theta)}{R^{2}} d F_{\theta} \int\left\{x_{2, I}^{u}(I, R ; \theta)\right\} d F_{\theta}} .
$$

which using Slutsky's equation

$$
x_{2, R}^{u}(I, R ; \theta)=x_{2, R}^{c}(I, R ; \theta)+x_{2, I}^{u}(I, R ; \theta) \frac{x_{2}^{u}(I, R ; \theta)}{R^{2}} .
$$

can be expressed as

$$
\frac{\operatorname{Cov}\left\{V_{I}(I, R ; \theta), \frac{x_{2}^{u}(I, R ; \theta)}{R^{2}}\right\} \int x_{2, I}^{u}(I, R ; \theta) d F_{\theta}}{\int x_{2, R}^{c}(I, R ; \theta) d F_{\theta}+\operatorname{Cov}\left\{x_{2, I}^{u}(I, R ; \theta), \frac{x_{2}^{u}(I, R ; \theta)}{R^{2}}\right\}} .
$$

This proves the proposition.

\subsection{Proof of Lemma 2}

Part 1. If preferences are homothetic, then

$$
\frac{I x_{2, I}^{u}(I, R ; \theta)}{x_{2}^{u}(I, R ; \theta)}=1
$$

This implies, first, that date 2 consumption is a normal good, so that $x_{2, I}^{u}(I, R ; \theta)>0$. Second, it implies that $\operatorname{Cov}\left\{x_{2, I}^{u}(I, R ; \theta), \frac{x_{2}^{u}(I, R ; \theta)}{R^{2}}\right\} \geq 0$, which in turn implies assumption 2 .

Part 2. Let $K$ be a compact set containing the optimal values of $(R, I)$ for $1 \geq \gamma \geq 0$. Then there exists $\gamma$ such that for all $(R, I) \in K$

$$
\left|\operatorname{Cov}\left\{x_{2, I}^{u}(I, R ; \theta), \frac{x_{2}^{u}(I, R ; \theta)}{R^{2}}\right\}\right|<M \sigma_{F^{\gamma}}^{2}
$$

The Lemma follows.

\subsection{Proof of Theorem 1}

Assumption 1 ensures that $\frac{\partial}{\partial \theta}\left(\frac{x_{2}^{u}(I, R ; \theta)}{R^{2}}\right)>0$. Then we conclude that If $V_{I, \theta}\left(I, R^{*} ; \theta\right)>0$ for all $\theta$, then $\operatorname{Cov}\left\{V_{I}\left(I^{*}, R^{*} ; \theta\right), \frac{x_{2}^{u}\left(I^{*}, R^{*} ; \theta\right)}{R^{* 2}}\right\}>0$; if $V_{I, \theta}\left(I, R^{*} ; \theta\right)<0$ for all $\theta$, then $\operatorname{Cov}\left\{V_{I}\left(I^{*}, R^{*} ; \theta\right), \frac{x_{2}^{u}\left(I^{*}, R^{*} ; \theta\right)}{R^{* 2}}\right\}<$ 0 .

We now show a lemma that determines how $V_{I}\left(I, R^{*} ; \theta\right)$ depends on preferences. 
Lemma $3 V_{I, \theta}\left(I, R^{*} ; \theta\right)>0$ for all $\theta$, if preferences are discount factor shocks as in example 1. $V_{I, \theta}\left(I, R^{*} ; \theta\right)<0$ for all $\theta$, if preferences are liquidity shocks as in example 2 ; if preferences are valuation-neutral shocks as in example $3, V_{I, \theta}\left(I, R^{*} ; \theta\right)=0$ for all $\theta$.

Proof. We have

$$
V(I, R ; \theta)=\max _{x_{1}, x_{2}} u\left(x_{1}, x_{2} ; \theta\right)
$$

subject to

$$
x_{1}+\frac{x_{2}}{R} \leq I .
$$

Suppose first that preferences are given by $u\left(x_{1}\right)+\theta u\left(x_{2}\right)$. Then, substituting $x_{1}$ using the budget constraint, we can rewrite this problem as

$$
V(I, R ; \theta)=\max _{x_{2}} \hat{u}\left(I-\frac{x_{2}}{R}\right)+\theta u\left(x_{2}\right) .
$$

By the Envelope theorem, we have

$$
V_{\theta}(I, R ; \theta)=\hat{u}\left(x_{2}^{u}(I, R, \theta)\right)
$$

Hence,

$$
V_{I, \theta}=\hat{u}^{\prime}\left(x_{2}^{u}(I, R, \theta)\right) x_{2, I}^{u}(I, R, \theta)>0 .
$$

Suppose now that preferences are given by $\frac{1}{\theta} u\left(x_{1}\right)+u\left(x_{2}\right)$. By the Envelope theorem, we have

$$
V_{\theta}(I, R ; \theta)=-\frac{1}{\theta^{2}} \hat{u}\left(x_{1}^{u}(I, R, \theta)\right) .
$$

Hence

$$
V_{I, \theta}=\frac{-1}{\theta^{2}} \hat{u}^{\prime}\left(x_{2}^{u}(I, R, \theta)\right) x_{1, I}^{u}(I, R, \theta)<0 .
$$

For the value neutral preferences $V_{I, \theta}=0$.

This proves the Lemma.

\subsection{Proof of Theorem 2}

Note that the incentive compatibility constraint can be rewritten as

$$
u\left(c_{1}(\theta), c_{2}(\theta) ; \theta\right) \geq \tilde{V}\left(c_{1}\left(\theta^{\prime}\right)+\frac{c_{2}\left(\theta^{\prime}\right)}{R}, R ; \theta\right) \text { for all } \theta, \theta^{\prime} \text { in } \Theta
$$

and in turn

$$
u\left(c_{1}(\theta), c_{2}(\theta) ; \theta\right) \geq \tilde{V}\left(\max _{\theta^{\prime}} c_{1}\left(\theta^{\prime}\right)+\frac{c_{2}\left(\theta^{\prime}\right)}{R}, R ; \theta\right) .
$$


This is equivalent to

$$
\begin{aligned}
c_{1}(\theta)+\frac{c_{2}(\theta)}{R} & =\max _{\theta^{\prime}} c_{1}\left(\theta^{\prime}\right)+\frac{c_{2}\left(\theta^{\prime}\right)}{R}, \\
c_{1}(\theta) & =x_{1}^{u}\left(c_{1}(\theta)+\frac{c_{2}(\theta)}{R}, R ; \theta\right) \text { and } c_{2}(\theta)=x_{2}^{u}\left(c_{1}(\theta)+\frac{c_{2}(\theta)}{R}, R ; \theta\right) .
\end{aligned}
$$

Therefore, allocations that satisfy the incentive compatibility constraints are entirely characterized by the following: there exists an equilibrium income level $I$ such that for all $\theta$,

$$
c_{1}(\theta)=x_{1}^{u}(I, R ; \theta) \text { and } c_{2}(\theta)=x_{2}^{u}(I, R ; \theta)
$$

Of course the level of utility achieved ex post by an agent of type $\theta$ is then given by $V(I, R ; \theta)$. This proves the theorem.

\subsection{Proof of Proposition 4}

With the logarithmic utility, uncompensated demands, and the indirect utility function have a very simple form:

$$
\begin{aligned}
x_{1}^{u}(I, R ; \theta) & =I \frac{\theta_{1}}{\theta_{1}+\theta_{2}}, x_{2}^{u}(I, R ; \theta)=I R \frac{\theta_{2}}{\theta_{1}+\theta_{2}} \\
V(I, R ; \theta) & =\left(\theta_{1}+\theta_{2}\right) \log (I)+\theta_{1} \log \left(\frac{\theta_{1}}{\theta_{1}+\theta_{2}}\right)+\theta_{2} \log \left(\frac{R \theta_{2}}{\theta_{1}+\theta_{2}}\right) .
\end{aligned}
$$

We can rewrite the problem of finding the optimal liquidity adequacy requirement (22) using the functional form of the utility and dropping constants in the objective function as

$$
\max _{I, R} \int\left\{\left(\theta_{1}+\theta_{2}\right) \log (I)+\theta_{2} \log (R)\right\} d F_{\theta}
$$

subject to

$$
\int I\left\{\frac{\theta_{1}}{\theta_{1}+\theta_{2}}+\frac{R}{\hat{R}} \frac{\theta_{2}}{\theta_{1}+\theta_{2}}\right\} d F_{\theta} \leq e .
$$

The first order condition for $I$ and $R$, respectively, are given by

$$
\begin{gathered}
\int\left[\theta_{1}+\theta_{2}\right] d F_{\theta}=\lambda I \int\left\{\frac{\theta_{1}}{\theta_{1}+\theta_{2}}+\frac{R}{\hat{R}} \frac{\theta_{2}}{\theta_{1}+\theta_{2}}\right\} d F_{\theta} \\
\frac{1}{R} \int \theta_{2} d F_{\theta}=\frac{\lambda I}{\hat{R}} \int \frac{\theta_{2}}{\theta_{1}+\theta_{2}} d F_{\theta},
\end{gathered}
$$

where $\lambda>0$ is a multiplier on the resource constraint (61).

Manipulating these first order conditions we obtain the closed form solution for the interest rate $R^{*}$ associated with the optimal liquidity requirement: 


$$
\frac{R^{*}}{\hat{R}}=\frac{E \theta_{2}}{E \theta_{1}} \frac{E \frac{\theta_{1}}{\theta_{1}+\theta_{2}}}{E \frac{\theta_{2}}{\theta_{1}+\theta_{2}}}
$$

where $E$ represent the expectation with respect to $F(\theta)$.

We can also find the optimal level of the liquidity requirement. Using feasibility to substitute for $I$ we obtain the optimal liquidity requirement $i^{*}$ is given by:

$$
i^{*}=\int x_{1}^{u}(I, R ; \theta) d F_{\theta}=\frac{e \int \frac{\theta_{1}}{\theta_{1}+\theta_{2}} d F_{\theta}}{\int\left\{\frac{\theta_{1}}{\theta_{1}+\theta_{2}}+\frac{R^{*}}{\hat{R}^{2}} \frac{\theta_{2}}{\theta_{1}+\theta_{2}}\right\} d F_{\theta}} .
$$

We now substitute for the $\theta_{1}, \theta_{2}$ for our three formulations of preferences and summarize the closed form solution in the proposition that follows.

\subsection{Proof of Proposition 5}

Consider the following consumption problem that gives the indirect utility of an agent who is allocated with income $I$ and who can trade on the private markets with the interest rate $R$ :

$$
V(I, R ; \theta)=\max _{c_{1}, c_{2} \geq 0} U\left(c_{1}, c_{2} ; \theta\right)
$$

s.t.

$$
c_{1}+\frac{c_{2}}{R} \leq I
$$

Denote by $\left(x_{1}(I, R ; \theta), x_{2}(I, R ; \theta)\right)$ the maximand of this problem.

The problem of finding the best liquidity requirement is given by (this is analogue of problem $(22))$ :

$$
\max _{I, R} \pi V(I, R ; 0)+(1-\pi) V(I, R, 1)
$$

s.t.

$$
\pi\left(x_{1}(I, R ; 0)+\frac{x_{2}(I, R ; 0)}{\hat{R}}\right)+(1-\pi)\left(x_{1}(I, R ; 1)+\frac{x_{2}(I, R ; 1)}{\hat{R}}\right) \leq e .
$$

We want to verify that the unconstrained allocation solving $S P^{1}$ or $S P^{2}$ is a solution to the program (68) for the values of $I$ and $R$ defined below. Consider the following system in $(I, R)$

$$
\begin{aligned}
u^{\prime}(I) & =\rho \hat{R} u^{\prime}(R I), \\
I & =\frac{e}{\pi+(1-\pi) \frac{R}{\hat{R}}} .
\end{aligned}
$$

The result that $(I, R)$ defined in (70) and (71) satisfy the first order conditions of both (31) and (68) follows immediately from the following observations.

$$
V(I, R ; 0)=u(I), x_{1}(I, R ; 0)=I, \text { and } x_{2}(I, R ; 0)=0
$$


and if $R \geq 1$

$$
V(I, R ; 1)=\rho u(R I), x_{1}(I, R ; 1)=0, \text { and } x_{2}(I, R ; 1)=R I
$$

and if $R<1$

$$
V(I, R, 1)=\rho u(I), x_{1}(I, R ; 1)=I, \text { and } x_{2}(I, R ; 1)=0 .
$$

Combining equations (70) and (71) we see that $R$ is a solution to

$$
\frac{u^{\prime}\left(\frac{e}{\pi+(1-\pi) \frac{R}{\hat{R}}}\right)}{u^{\prime}\left(\frac{R e}{\pi+(1-\pi) \frac{R}{\hat{R}}}\right)}-\rho \hat{R}=0
$$

Denote by $f(R)$ the left hand side of $(72)$. Note that $f(R)$ is increasing and $f(1)=1-\rho \hat{R}<0$, so that the solution to (70) and (71) involves $R>1$. Now since the coefficient of relative risk aversion is everywhere greater than 1 , we have

$$
\frac{u^{\prime}\left(\frac{e}{\pi+(1-\pi) \frac{R}{\hat{R}}}\right)}{R u^{\prime}\left(\frac{R e}{\pi+(1-\pi) \frac{R}{\hat{R}}}\right)} \geq 1
$$

which implies that $f(\rho \hat{R}) \geq 0$, with equality if $\hat{u}(c)=\log (c)$. This concludes the proof that the allocation $S P^{1}$ coincides with the problem of finding the optimal liquidity requirement for some $R \in(1, \rho \hat{R}]$ and

$$
I=\frac{e}{\pi+(1-\pi) \frac{R}{\hat{R}}}
$$




\section{References}

[1] Albanesi, S., 2006, Optimal Taxation of Entrepreneurial Capital with Private Information, NBER WP 12419 and CEPR DP 5647.

[2] Allen, F., 1985, "Repeated Principal-Agent Relationships with Lending and Borrowing," Economics Letters, 17, 27-31.

[3] Allen, G. and Gale, D., 2003, Reserve Regulation: In Search of a Rationale, in Economics for an Imperfect World: Essays in Honor of Joseph Stiglitz edited by R. Arnott, B. Greenwald, R. Kanbur and B. Nalebuff, Cambridge, MA: MIT Press, 83-109

[4] Allen, G. and Gale, D., 2004, Financial Intermediaries and Markets, Econometrica, 72(4), 1023-1061.

[5] Arnott, R. and Stiglitz, J.E., 1986, Moral Hazard and Optimal Commodity Taxation, Journal of Public Economics 29, 1-24

[6] Arnott, R. and Stiglitz, J.E., 1990, The Welfare Economics of Moral Hazard. In H. Louberge ed. ed., Information and Insurance: Essays in Memory of Karl H. Borch, Norwell, MA: Kluwer, 91-121

[7] Atkeson, Andrew and Lucas, Robert E, Jr, 1992, "On Efficient Distribution with Private Information," Review of Economic Studies, Blackwell Publishing, vol. 59(3), pages 427-53, July.

[8] Bisin, A., J. D. Geanakoplos, P. Gottardi, E. Minelli, and H. Polemarchakis, 2001, Markets and Contracts, Journal of Mathematical Economics, forthcoming.

[9] Bisin, A. and Rampini, A., 2006, "Exclusive Contracts and the Institution of Bankruptcy", Economic Theory, 27 (2006), 277-304.

[10] Bhattacharya, S and D. Gale, 1987, Preference Shocks, Liquidity and Central Bank Policy, in W Barnett and K Singleton (eds), New approaches to monetary economics, Cambridge University Press, New York.

[11] Caballero, R. J. and Krishnamurthy, A., 2003, Smoothing Sudden Stops, forthcoming in Journal of Economic Theory.

[12] Chiappori, Pierre-Andre, Macho, Ines, Rey, Patrick and Salanie, Bernard, 1994., "Repeated moral hazard: The role of memory, commitment, and the access to credit markets," European Economic Review, Elsevier, vol. 38(8), pages 1527-1553, October.

[13] Diamond, D., 1997, Liquidity, Banks and Markets, Journal of Political Economy, 105, 928-956 
[14] Diamond, D. and Dybvig, P., 1983, Bank Runs, Liquidity, and Deposit Insurance, Journal of Political Economy, 91, 401-419

[15] Freixas, X. and J-C Rochet.,1997, Microeconomics of Banking, Cambridge, Mass.: MIT.

[16] Geanakoplos, J. and H. Polemarchakis, 1986, Existence, Regularity, and Constrained Suboptimality of Competitive Allocations When the Asset Market Is Incomplete, in Walter Heller, Ross Starr, and David Starrett eds. Essays in honor of Kenneth J. Arrow: Volume 3, Uncertainty, information, and communication. Cambridge, New York and Sydney: Cambridge University Press, 65-95. Also reprinted in Debreu, Gerard, ed. (1996). General equilibrium theory. Volume 2. Elgar Reference Collection. International Library of Critical Writings in Economics, no. 67. Cheltenham, U.K.: Elgar; distributed by Ashgate, Brookfield, Vt. 67-97.

[17] Golosov, M. and Tsyvinski, A., 2007, Optimal Taxation with Endogenous Insurance Markets, forthcoming in Quarterly Journal of Economics.

[18] Golosov, M., Kocherlakota, N. and Tsyvinski, A., 2003. Optimal Indirect and Capital Taxation. Review of Economic Studies 70, 569-587

[19] Golosov, Tsyvinski, A, and I. Werning, 2006, New Dynamic Public Finance: A User's Guide, forthcoming in NBER Macroeconomics Annual.

[20] Gorton, Gary and A. Winton, 2002, Financial Intermediation, National Bureau for Economic Research (Cambridge, MA) Working Paper 8928.

[21] Greenwald, B.C. and Stiglitz, J.E., 1986, Externalities in Economies with Imperfect Information and Incomplete Markets, Quarterly Journal of Economics, 101, 229-264

[22] Guesnerie, R., 1998, A Contribution to the Pure Theory of Taxation. Cambridge University Press.

[23] Hammond, Peter J, 1987, Markets as Constraints: Multilateral Incentive Compatibility in Continuum Economies, Review of Economic Studies, Blackwell Publishing, vol. 54(3), pages 399-412, July.

[24] Hellmann, T., K. Murdock and J. Stiglitz (1998). Liberalization, Moral Hazard in Banking, and Prudential Regulation: Are Liquidity Requirements Enough?, Working Paper 1466R, Graduate School of Business, Stanford University.

[25] Hellmann, T., K. Murdock and J. Stiglitz, 2000, Liberalization, Moral Hazard in Banking, and Prudential Regulation: Are liquidity Requirements Enough?, American Economic Review, 90, $147-165$.

[26] Hellwig, M., 1994, Liquidity Provision, Banking, and the Allocation of Interest Rate Risk, European Economic Review, 38, 1363-1389 
[27] Hellwig, M., 1998, Banks, Markets, and the Allocation of Risks in an Economy, Journal of Institutional and Theoretical Economics, 154, 328-345

[28] Holmstrom, B. and J. Tirole, "Private and Public Supply of Liquidity" , Journal of Political Economy , Vol. 106.

[29] Jacklin, C.J., 1987, Demand Deposits, Trading Restrictions, and Risk Sharing, in Contractual Arrangements for Intertemporal Trade, ed. E. Prescott and N. Wallace, Minneapolis: University of Minnesota Press, 26-47.

[30] Kocherlakota, N., 2006, "Advances in Dynamic Optimal Taxation," Advances in Economics and Econometrics, Theory and Applications: Ninth World Congress of the Econometric Society.

[31] Lorenzoni, G., 2006, Liquidity Crises and Efficiency, MIT mimeo.

[32] Merton, R., 1977, An Analytic Derivation of the Cost of Deposit Insurance and Loan Guarantees: An Application of Modern Option Pricing Theory, Journal of Banking and Finance 1, $3-11$.

[33] Prescott, E. and R. Townsend, 1984, Pareto Optima and Competitive Equilibria with Adverse Selection and Moral Hazard, Econometrica 52, 21-45.

[34] von Thadden, E.-L., 1999, Liquidity Creation through Banks and Markets: Multiple Insurance and Limited Market Access, European Economic Review, 43, 991-1006. 